NBER WORKING PAPER SERIES

\title{
A THEORY OF DEBT MATURITY: THE LONG AND SHORT OF DEBT OVERHANG
}

\author{
Douglas W. Diamond \\ Zhiguo He \\ Working Paper 18160 \\ http://www.nber.org/papers/w18160
NATIONAL BUREAU OF ECONOMIC RESEARCH
1050 Massachusetts Avenue
Cambridge, MA 02138
June 2012

Booth School of Business, University of Chicago, and NBER. The authors gratefully acknowledge research support from the Center for Research in Security Prices at Chicago Booth. Diamond gratefully acknowledges support from the Nation Science Foundation. We thank two referees, seminar participants at MIT Sloan, OSU Fisher, Chicago Booth, Columbia, Yale, Harvard, UCLA, NBER 2010 Corporate Finance meeting in Chicago, AFA 2011 in Denver, Nittai Bergman, Hui Chen, Gustavo Manso, Gregor Matvos, Victoria Ivashina, Henri Pages, Raghu Rajan, Berk Sensoy, Jeremy Stein, Rene Stulz, Sheridan Titman and especially Stewart Myers and Charles Kahn for insightful comments. The views expressed herein are those of the authors and do not necessarily reflect the views of the National Bureau of Economic Research.

NBER working papers are circulated for discussion and comment purposes. They have not been peerreviewed or been subject to the review by the NBER Board of Directors that accompanies official NBER publications.

(C) 2012 by Douglas W. Diamond and Zhiguo He. All rights reserved. Short sections of text, not to exceed two paragraphs, may be quoted without explicit permission provided that full credit, including (C) notice, is given to the source. 
A Theory of Debt Maturity: The Long and Short of Debt Overhang

Douglas W. Diamond and Zhiguo He

NBER Working Paper No. 18160

June 2012

JEL No. G32

\begin{abstract}
$\underline{\text { ABSTRACT }}$
Debt maturity influences debt overhang: the reduced incentive for highly- levered borrowers to make real investments because some value accrues to debt. Reducing maturity can increase or decrease overhang even when shorter-term debt's value depends less on firm value. Future overhang is more volatile for shorter-term debt, making future investment incentives volatile and influencing immediate investment incentives. With immediate investment, shorter-term debt typically imposes lower overhang; longer-term debt can impose less if firm value is more volatile in bad times. For future investments, reduced correlation between the value of assets-in-place and profitability of investment increases the overhang of shorter-term debt.
\end{abstract}

Douglas W. Diamond

Booth School of Business

University of Chicago

5807 S Woodlawn Avenue

Chicago, IL 60637

and NBER

douglas.diamond@ chicagobooth.edu

Zhiguo He

University of Chicago

Booth School of Business

5807 S. Woodlawn Avenue

Chicago, IL 60637

and NBER

zhiguo.he@chicagobooth.edu 


\section{Introduction}

This paper studies the effects of the debt maturity on current and future real investment decisions of an owner of equity (or a manager who is compensated by equity). Our analysis is based on debt overhang first analyzed by Myers (1977), who points out that outstanding debt may distort the firm's investment incentives downward. A reduced incentive to undertake profitable investments when decision makers seek to maximize equity value is referred to as a problem of "debt overhang," because part of the return from a current new investment goes to make existing debt more valuable.

Myers (1977) suggests a possible solution of short-term debt to the debt overhang problem. In part, this extends the idea that if all debt matures before the investment opportunity, then the firm without debt in place can make the investment decision as if an all-equity firm. Hence, following this logic, debt that matures soon--although after relevant investment decisions, as opposed to before--should have reduced overhang.

However, short-term debt is known to have several disadvantages. For firms without access to outside funds to meet debt repayments, short-term debt can lead to early firm closure and liquidation (e.g., Diamond (1991), Gertner and Scharfstein (1991)). More relevant to our paper, Gertner and Scharfstein (1991) show that, conditional on ex-post financial distress, making a fixed promised debt payment due earlier (i.e., shorter-term) raises the market value of the debt and thus the firm's market leverage, leading to more debt overhang ex-post. In addition, certain drawbacks of short-term debt have also been suggested by some quantitative models (Titman and Tsyplakov (2007), Moyen (2007)) that focus on equity holders' differential abilities and incentives to adjust leverage in response to new information given different debt maturity structures. ${ }^{1}$

Our paper aims to provide a thorough analysis on the effects of debt maturity on the equity incentives to undertake both current and future investments, and, more importantly, to identify the forces that determine overhang. We show why the ideas based on Myer's suggestion have merit, and show how and why they can be reversed under different settings. Throughout, we first illustrate our results via simple examples; these results are then generalized in the context of standard models used by practitioners and researchers, allowing us to establish their generality and introduce more complicated issues.

\footnotetext{
${ }^{1}$ For more details, see literature review at the end of the introduction.
} 
We stress the importance of the relative timing of investment decisions, debt maturity, and news about the prospect of the firm's existing assets (including past investment). In a nutshell, shorter-term debt--because of earlier repayment and less risk sharing-usually receives less benefit from an immediate investment, leading to a lower overhang. This is consistent with the ideas in Myers (1977). However, for firms with future investment opportunities, the future prospects and value of existing assets fluctuate before investment decisions, and the sharing of less risk by shorter-term debt implies more volatile equity value and hence more volatile debt overhang. Shorter-term debt thus imposes stronger overhang especially in bad times, and this result is related to Gertner and Scharfstein (1991) and Titman and Tsyplakov (2007).

The first setting that we analyze is the one with immediate investment decisions that are made right after the issuance of the debt but before any new information is released. Extending the logic of Myers (1977), shorter-term debt would impose less overhang on immediate investment, and we illustrate this result by simple examples. There, a shorter maturity makes the debt market value less sensitive to changes in the firm value, and equity holders' investment incentives are distorted (downward) exactly by the increased value of claims other than equity. However, this intuitive idea is incomplete, as we further show that the effect of maturity could reverse, depending on the timing of investment decisions and the way that uncertainty is resolved over time (i.e., state-dependent volatility).

Moving from examples to standard model frameworks, Proposition 1 in Section 3 proves that, holding the debt value and hence the firm's leverage constant, ${ }^{2}$ shorter-term debt imposes less overhang on immediate investment in the classic setting based on Black and Scholes (1973) and Merton (1974). To our knowledge, this analytical result is new to the literature, and appears to be the basis for the logic extending Myers (1977).

In the Black-Scholes-Merton setting, the asset volatility is constant. With covariation of volatility and the value of assets-in-place, especially when the timing of resolution of uncertainty leads to sufficiently increased remaining uncertainty after bad outcomes, shorter-term debt may have a stronger overhang even for immediate investment decisions. We show this by an example in Section 2.5, more formally by adding state dependent volatility to the Black-Scholes-Merton

\footnotetext{
${ }^{2}$ Holding constant the borrower's leverage has not been stressed in previous studies about the effect of maturity on debt overhang, e.g., Gertner and Scharfstein (1991).
} 
model in Section 3.3. These results produce new implications for the effect of debt maturity on immediate investment incentives.

In the second setting that we analyze, firms have many investment opportunities in the present and the future. With future investment opportunities, the distribution of debt overhang in the future is relevant because the incentive to invest depends on the overhang prevailing at the time of future investment. In addition, debt overhang influences the equity's decision to default on debt, ${ }^{3}$ and default implies that investment opportunities thereafter are not taken. In general, exactly because shorter-term debt is less sensitive to changes in firm value, it leads to more volatile future equity value and hence more volatile future overhang: Equity has weak investment incentives and is more likely to default after poor performance of the firm's assets-inplace, and has strong investment incentives after good performance. Examples in Section 2.4 illustrate this logic and some of its implications. For firms with investment opportunities in the future, a balance of maintaining investment incentives in future good and bad states leads to an optimal interior maturity structure. This mechanism is formally illustrated in Section 4 where we study a dynamic model that generalizes Leland (1994b, 1998) to include a series of future investment opportunities.

We further show that when investment opportunities are positively correlated with the firm's assets-in-place, it is beneficial to have a shorter debt maturity, which imposes lower (higher) debt overhang in times with high (low) values of assets-in-place and hence better (worse) investment opportunities. This result offers a new perspective on the empirical predictions regarding growth firms and debt maturity. For growth firms with uncertain investment opportunities where existing investment projects have realizations that are positively correlated with the value of new investment opportunities, shorter-term debt is preferred. However, for a growth firm with known future opportunities or the one where realized asset returns are not very informative about future opportunities, investment incentives are more efficient with longer-term debt. On the other extreme, mature firms that require timely maintenance to replace unexpectedly high depreciation in times of low cash flows should choose even longer-term debt. This perspective is different from the existing idea that firms with substantial future investment opportunities should choose shorter-term debt.

\footnotetext{
${ }^{3}$ The interpretation of endogenous default given debt burden as "underinvestment" due to debt overhang, is mentioned in, for example, Lambrecht and Myers (2008) and He (2011).
} 
In our dynamic setting with multiple investment opportunities, today's investment benefit is positively related to future investment policies. Because shorter-term debt triggers earlier default which eliminates future growth opportunities, this negative force may feed back to today and undermine current investment incentives. Intuitively, if future growth extending today's investment will not occur, it makes current investment less attractive. Interestingly, in contrast to a static setting where riskless debt cannot impose any overhang, Section 4.4 shows that in our dynamic setting a policy of (almost) riskless ultra-short debt may cause strong overhang on current investment.

Our framework focuses on decisions during the period before debt refinancing and thus fits well with the empirical literature in which short-term debt is often classified as that with maturity within three years (e.g., Johnson (2003)). Indeed, empirical work on debt maturity based on the hypothesis of reduced overhang of shorter-term debt, which implies the use of more short-term debt by "growth" firms with large investment opportunities, has had mixed success for reasons related to our findings in this paper. ${ }^{4}$

Short-term overhang is related to, but distinct from, the idea that shorter-term debt maturity increases the control rights of lenders to discipline management, e.g., Benmelech (2006), Calomiris and Kahn (1991), Diamond (1991), Diamond and Rajan (2001a), Flannery (1994), and Leland (1998). ${ }^{5}$ Short-term debt provides discipline in part because short-term lenders do not sit idly while a borrower misbehaves--they demand payment on maturity. This is closely related to our point that short-term debt can have severe overhang when firm value declines after the debt was issued. From this perspective, our paper extends the results in Gertner and Scharfstein (1991) that for a given total promised (but risky) payment to debt holders, ex-post debt overhang is made worse if more of the fixed amount is due sooner. Making a fixed payment due earlier raises the market value of the debt and thus the firm's market leverage, increasing ex-post overhang. Our paper emphasizes the timing of investment, and examines ex-ante effects of maturity on debt overhang for a given initial leverage to isolate it from the pure leverage effect. ${ }^{6}$ As a result, our

\footnotetext{
${ }^{4}$ For instance, Barclay and Smith (1995) and Guedes and Opler (1996) document a negative relation between maturity and growth opportunities, while Stohs and Mauer (1996) and Johnson (2003) find a positive relation once controlling for firm leverage.

${ }^{5}$ It also differs from theories of maturity structure where short-maturity debt is attractive to borrowers with private information that their future credit rating may improve, e.g., Flannery (1986) and Diamond (1991), or the idea that short-term debt entices runs due to coordination issues, e.g., Diamond and Dybvig (1983), He and Xiong (2011).

${ }^{6}$ We study the effect of maturity on debt overhang by fixing the leverage exogenously for an additional reason. Tax based theories suggest leverage increases when current and future investment opportunities become more profitable,
} 
paper reconciles the result in Gertner and Scharfstein (1991) that shorter-term debt has more ex-post overhang, with the suggestion in Myers (1977) that shorter-term debt has less ex-ante overhang.

We describe several important effects of debt maturity that have not received much formal analysis in the literature. We have new results on the effect of debt maturity on debt overhang with an immediate investment in the Black-Scholes-Merton setting, holding leverage constant. Our result on the effects of reduced volatility when firm value is low has not been suggested previously. We argue in the conclusion that this result applies especially well to financial institutions such as banks. Our analytical study for the case of dynamic investment opportunities in the Leland setting is related to existing quantitative studies on the effect of debt overhang. These studies focus on leverage adjustments to trade off the tax shield against physical costs of default, and each adds some other frictions. Both of them suggest that short-term debt is not a perfect solution to overhang. Titman and Tsyplakov (2007) use a model based on Leland (1998) but with costs of adjusting leverage, and find that short-term debt improves investment incentives but triggers earlier default. Relative to Titman and Tsyplakov, our paper with a simpler setting provides analytical results, and further points out that with inter-temporally linked investment incentives short-term debt may hurt current investment decisions due to earlier default in the future. In another closely related paper, Moyen (2007) studies the effect of debt maturity on overhang directly but focuses on an assumed asymmetry in leverage adjustment, i.e., the leverage cannot be adjusted if there is long-term debt, but can be adjusted every period if short-term debt is issued. Moyen finds that, compared to long-term debt, a firm with short-term debt has higher (lower) leverage in good (bad) times, but the overall overhang effect is similar across both maturity structures. In contrast, we follow Leland (1994b, 1998) where the debt burden is fixed to focus only on maturity.

Our analysis of dynamic investment opportunities is based on Leland (1994b, 1998) so that the debt refinancing rate (which is inversely related to the firm's debt maturity structure) is fixed at a constant. The dynamic adjustment of debt maturity is beyond our paper, and we provide some discussion in Section 4.6

while control and pecking order theories suggest the opposite. There is not an agreement in empirical studies about these determinants of dynamic adjustments to firm leverage (see e.g., Fama and French (2002)). 
The rest of the paper is organized as follows. We give a series of examples in Section 2 to illustrate the key ideas of this paper. Section 3 provides a model with a single investment decision based on the Black-Scholes-Merton setting, and Section 4 provides a dynamic Lelandtype model with many future investment decisions. In Section 5 we conclude.

\section{Debt Overhang: Assumptions and Examples}

We first describe debt overhang and related assumptions, and then provide numerical examples to illustrate the main insights delivered by this paper.

\subsection{Debt Overhang and Key Assumptions}

Debt overhang, first formalized by Myers (1977), captures the insight that investment often leads to external benefits that accrue to the firm's debt claims. These external benefits consequently lead equity holders (or equivalently managers who are paid in equity) who make investment decisions to internalize only part of investment benefits, and hence to underinvest relative to the level that maximizes the total value of the firm.

To study debt overhang, we will make the following assumptions throughout.

1. We examine standard debt contracts with two characteristics: promised face value and maturity.

2. We assume that at time 0 the firm has to raise a certain amount of financing through debt. Our analysis fixes the initial market value of the debt, because we study debt maturity for a given amount of leverage. However, we do not specify the particular reasons for why firms use debt. This is partly because all reasons for using debt must take account of the potential effect on investment incentives, and partly because there is no empirical consensus on the relative merits of various reasons (e.g., tax or managerial incentives for decisions other than investment; see footnote 6).

3. We assume that it is equity holders who control the firm and who carry out investment. This captures the idea that corporate decisions are delegated to those in control, rather than decided by a consensus of outside investors. Investment opportunities are lost during bankruptcy, and we impose no exogenous bankruptcy cost otherwise. 


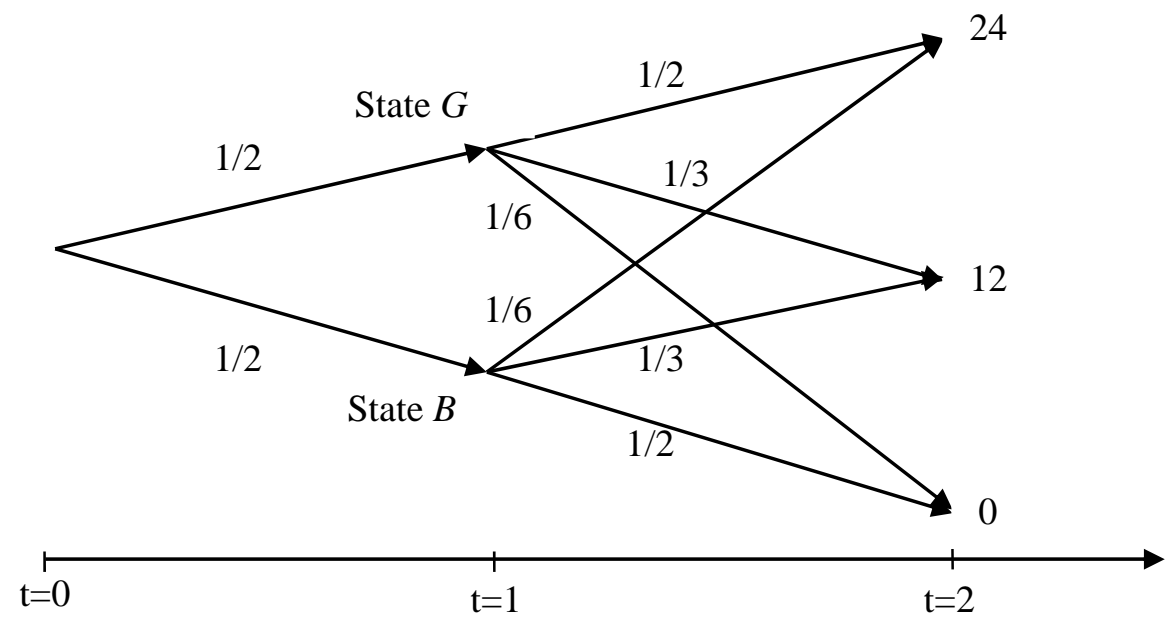

Figure 1: Time line for numerical examples, with conditional probabilities denoted on each path. As shown, the conditional distribution given state $G$ is $\{1 / 2,1 / 3,1 / 6\}$. We will consider an alternative conditional distribution of $\{1 / 3,2 / 3,0\}$ given state $G$.

4. We assume that debt cannot be renegotiated to bribe managers to make alternative decisions. This assumption is especially relevant to debt with many holders, as opposed to a single bank or individual. ${ }^{7}$

5. We focus on investment projects that are subject to "debt overhang” only, i.e., projects that weakly increase or leave unchanged the value of each of its debt and equity claims. We do not consider "risk shifting" where a large increase in the risk profile of existing assets may cause a redistribution of value across equity and debt claims, as described in Jensen and Meckling (1976). Throughout this paper we focus on incremental investments which have less chance of introducing the possibility of "risk shifting."

6. To focus on maturity only, debts with different maturities are assumed to have same seniority during bankruptcy. ${ }^{8}$

\subsection{Example Setting}

We begin by showing our results via numerical examples. We later will show similar results based on standard Black-Scholes-Merton and Leland models.

Assets-in-place. As in Figure 1, the firm has assets-in-place which bring final cash flows at date 2 , with three potential outcomes $\{24,12,0\}$ each occurring with probability $1 / 3$ from the perspective of date 0 . There are no cash flows on other dates. The discount rate is zero.

\footnotetext{
${ }^{7}$ Gertner and Scharfstein (1991) show that debt that cannot be renegotiated (especially if short-term) can impede renegotiation of other debt. In that sense, even renegotiation is subject to overhang.

${ }^{8}$ This is related to the dilution effect when firms refinance their maturing debt in a dynamic model. We rule out dilution by adopting the Leland (1994b, 1998) setting in Section 4. For dilution issues, see Diamond (1993), Brunnermeier and Oehmke (2011), and Hackbarth and Mauer (2011), and related discussion in Section 4.6.2.
} 
Information. At date 1 some public information arrives. At state $B$ which occurs with probability $1 / 2$, the news is bad, and the conditional probabilities to reach the final outcomes become $\{1 / 6,1 / 3,1 / 2\}$. Symmetrically, good news arrives at state $G$ with a probability of $1 / 2$, and the conditional probabilities for three outcomes become $\{1 / 2,1 / 3,1 / 6\}$.

Debt face values and maturities. Suppose that the firm needs to raise 8.25 at date 0 . The debt can be either long-term (repaid at date 2) or short-term (repaid at date 1), and they have face values of $F_{L}=12.75$ and $F_{S}=8.5$, respectively, to lead to the target date-0 market value of 8.25:

$$
\frac{1}{3} \times 12.75+\frac{1}{3} \times 12+\frac{1}{3} \times 0=8.25=\frac{1}{2} \times 8.5+\frac{1}{2} \times 8 .
$$

The left hand side describes the payoffs to long-term debt, which is only paid in full (i.e., 12.75) with probability $1 / 3$ at the outcome of 24 . The right hand side describes the short-term debt: with probability $1 / 2$, the firm in state $G$ pays debt holders the full face value 8.5 ; while with probability $1 / 2$ the firm in state $B$ defaults, and short-term debt holders recover the assets-in-place with a value of $8=24(1 / 6)+12(1 / 3)$.

Investment opportunities. For ease of illustration we only consider infinitesimal investment which improves the final payoff of the assets-in-place by $\varepsilon>0$. We do not specify the investment cost because debt overhang can be measured by the investment benefit that is captured by debt. The investment decision will be made only if its net present value exceeds the debt overhang.

Investment timings. We consider two different timings of investment. The first is that the firm invests at date 0 before the realization of state $G$ or $B$; and the second is that the firm invests only at date 1 after the realization of the news about the assets-in-place (state $G$ or $B$ ) but before the short-term debt matures. We believe both timing assumptions are empirically relevant.

\subsection{Date-0 Investment before Assets-in-place News: A Benchmark Result}

We first consider the case of single investment at date 0 , immediately after raising the debt. Many of the exiting ideas based on the discussion in Myers (1977) consider the effect of maturity on debt overhang in this particular setting.

We calculate the overhang as the expected benefit from the new investment that is captured by the debt with given maturities. Because the long-term debt face value $F_{L}=12.75$ exceeds the intermediate outcome 12 but below the highest outcome 24, the overhang occurs in both the middle and low states and thus is $2 / 3 \varepsilon$ (equity gets $1 / 3 \varepsilon$ ). For short-term debt, in state $B$ the firm 
value 8 is below the face value of short-term debt $F_{S}=8.5$. Short-term debt imposes an overhang of $1 / 2 \varepsilon$ as it captures all of the gain at state $B$ from the date- 0 investment. If the investment cost at date 0 is between $1 / 3 \varepsilon$ and $1 / 2 \varepsilon$, then this investment will be taken if and only if the firm uses short-term debt. In this example, long-term debt imposes more overhang than short-term debt does, consistent with the discussion of Myers (1977). We will formally show this result in Section 3 using a model based on Black-Scholes (1973) and Merton (1974).

This intuitive result relies upon two assumptions, which we will study in the following subsections. The first is about investment timing; we show that if equity holders make investment decision at date 1 after the news about assets-in-place, then the optimal maturity will depend on the details of the investment opportunities. The second is about the cash-flow distribution, and we show that even for date 0 investment, short-term debt may impose stronger overhang in a distribution featuring higher volatility following bad news.

\subsection{Future Investment: Date-1 Investment after News about Existing Assets}

Now suppose that investment opportunities are available only at date 1 , so that equity holders make investment decisions after the realization of the interim state but before the short-term debt matures. Consider the case of long-term debt first. At state $G$, the benefit from an infinitesimal investment that goes to debt holders is $1 / 2 \varepsilon$ (equity also gets $1 / 2 \varepsilon$ ); put differently, equity recovers the benefit from investment only at the outcome 24 which occurs with a conditional probability of $1 / 2$. A similar argument implies that at state $B$ the long-term debt overhang is $5 / 6 \varepsilon$ (equity gets $1 / 6 \varepsilon$ ). Hence, long-term debt imposes some overhang in both states, but it is never so severe that equity holders recover nothing from new investment. If the cost of investment is less than $1 / 6 \varepsilon$, for example, then there will be investment in both states.

In contrast, short-term debt is a hard contract that does not share as much risk with equity due to its requirement of full payment whenever possible on its short maturity. As a result, in state $G$ short-term debt imposes no overhang; but in state $B$ it imposes the most extreme overhang, which is $\varepsilon$ so that short-term debt holders capture the entire benefit of investment. To see this, the short-term debt becomes riskless at state $G$ (the firm value 16 exceeds the debt face value 8.5) and therefore will not capture any gain from new investment. However, at state $B$, the deteriorating assets-in-place with a value of 8 fall below the face value 8.5 , so that equity holders will default at state $B$. There, the debt overhang is the entire investment benefit $\varepsilon$, because if equity holders were to invest right before the short-term debt matures, debt holders would 
receive every dollar that new investment generates. If the cost of investment is less than $1 / 6 \varepsilon$, for example, then there will be investment only in state $G$ while there would be investment in both states with long-term debt.

There are two lessons that we learn from this example with date 1 investment. First, it shows that when the firm's assets-in-place fluctuates, a shorter-term debt generates a more countercyclical overhang (higher overhang for low values of the firm, or weak investment incentives in future bad times). Hence, when the firm's investment opportunities are present in the future, the optimal debt maturity that minimizes overall overhang will depend on the details of future investment opportunities in different states. This idea will be formally analyzed in the dynamic model in Section 4.

Second, we can relate the state-dependent conditional overhang in this example back to the average date-0 overhang calculated in Section 2.3. Indeed, the date 0 long-term debt overhang $2 / 3 \varepsilon$, is just the average of the overhangs conditional on state $G(5 / 6 \varepsilon)$ and on state $B(1 / 2 \varepsilon)$. Similarly, the date-0 short-term debt overhang $1 / 2 \varepsilon$ is the average of the conditional overhang in state $G(0)$ and in state $B(\varepsilon)$. Short-term debt imposes more volatile conditional overhang, but it turns out that given the particular distribution in this example, once taking the average at date 0 , short-term debt has a lower average overhang than long-term debt. The next example shows that it is possible to reverse the relative ordering of date- 0 overhang by twisting the cash-flow distribution, based on the idea that conditional volatilities can affect conditional overhang at different states.

\subsection{Date-0 Investment with Conditional Volatility}

Consider the date 0 investment setting as in Section 2.3, but modify the distribution to reduce the conditional variance of cash flows in state $G$. Let the new conditional probabilities given $G$ be $\{1 / 3,2 / 3,0\}$; the old conditional distribution of $\{1 / 2,1 / 3,1 / 6\}$ in Figure 1 is a mean-preserving spread over the new conditional distribution. Due to symmetry between states $G$ and $B$ in the old distribution, the new distribution features a lower variance conditional on state $G$ than state $B$.

Given the new cash-flow distribution which implies the date-0 probabilities over final cash flows to be $\{1 / 4,1 / 2,1 / 4\}$, we calculate the new face values needed to raise 8.25 , i.e., the longterm debt face value is reduced to $F_{L}=11$ while the short-term face value is unchanged at $F_{S}=8.5$ 
In this new example, the short-term overhang remains at $1 / 2 \varepsilon$, because the short-term debt value 8.5 is unaffected, and the firm value 8 in state $B$ still leads to default as in the previous benchmark example in Section 2.3. In fact, it is not surprising to have short-term debt overhang unchanged. To see this, note that conditional variances prevailing on date 1 govern the distribution of date 2 cash flows conditional on date 1 information, and as a result cannot affect the payoff of short-term debt at all. ${ }^{9}$ In contrast, the long-term overhang is reduced to $1 / 4 \varepsilon$ because the new long-term debt face value $F_{L}=11$ is below the intermediate outcome 12 . Here, although short-term debt shares less risk from the jump down in value at of date $1,{ }^{10}$ the shortterm debt ends up taking more of the future return from date- 0 investment, and hence a more severe overhang. ${ }^{11}$

What is the reason? As shown, the date-0 overhang is the average of future levels of overhang at different states. We observe from Section 2.4 that the relative severity between longand short-term overhang is state dependent, in that long- (short-) term debt imposes stronger (weaker) overhang in good states. Thus, the average overhang at date 0 depends on the magnitude of overhang conditional on future states.

Adjusting volatilities conditional on future states affects the relative magnitude of conditional overhang for debt with different maturities. As mentioned above, because short-term debt gets repaid at date 1 , the short-term overhang is not affected by date 1 conditional volatilities. However, for long-term debt, either a lower volatility in state $G$ or a higher volatility in state $B$ reduces overhang in the corresponding state. A lower volatility in the good state implies that there is little chance of default for a long period afterwards; in our new example, the firm with long-term debt never defaults in state $G$ (there is zero probability to have the outcome 0 ), implying zero overhang. A higher volatility in state $B$ implies that, despite a low current value, the assets-in-place are more likely to increase sufficiently to repay creditors before long-term debt matures, which reduces overhang as equity can recover benefits from investment in these

\footnotetext{
${ }^{9}$ For instance, the increased volatility conditional on state $B$ does not affect overhang for a small incremental investment. As long as the value of assets-in-place (after investment) is below the face value of short-term debt due before further resolution of uncertainty, all investment benefit following state $B$ goes to short-term debt holders.

${ }^{10}$ The market value of short-term debt is 8.5 (8) in state $G(B)$, while the market value of long-term debt is $11(5.5)$ in state $G(B)$. Hence the short-term debt still shares less risk than long-term debt.

${ }^{11}$ One cannot construct such an example with stronger short-term overhang under the old "symmetric" distribution.
} 
states. In this new example, the overhang in state $B$ is $1 / 2 \varepsilon .{ }^{12}$ Averaging out these levels of conditional overhang, the date 0 long-term overhang is $1 / 4 \varepsilon$.

In sum, volatility that is higher in the bad state or lower in the good state reduces long-term debt overhang for both states at date 1, which helps average out to a lower long-term debt overhang at date 0 . In contrast, the change in volatility after short-term debt matures has no effect on its overhang. This result and associated intuition will be further illustrated in Section 3.3 in the Black-Scholes-Merton framework.

\subsection{Plan of the Rest of the Paper}

So far we have used simple numerical examples to illustrate our main results. The rest of the paper formalizes these results using models that are commonly used by researchers and practitioners in corporate finance. In Section 3 we use the Black-Scholes-Merton model to study the maturity effect of debt overhang on immediate investment, which corresponds to the results shown in Section 2.3 and Section 2.5. We then adopt the Leland framework to study the role of debt maturity on overhang when the firm with fluctuating values of assets-in-place has access to investment opportunities over time. This analysis corresponds to the setting in Section 2.4 where a firm chooses investment after the realization of news about its assets-in-place.

\section{Immediate Investment in the Black-Scholes-Merton Model}

Much of the intuition that shorter-term debt enhances the incentive for investment decisions, such as Myers (1977), comes from the Black and Scholes (1973) model and the study of risky corporate debt in Merton (1974) where equity is a European call option with a strike price equal to the debt face to be repaid on its maturity date. This section analyzes the effect of maturity on debt overhang in a Black-Scholes-Merton setting. Although many have discussed the effect of maturity on debt overhang based on the discussion in Myers (1977), we are unaware of any existing formal analysis in the Black-Scholes-Merton setting.

\subsection{The Black-Scholes-Merton Setting}

The firm has some existing assets in place, with current market value denoted by $V_{0}$. The asset value follows a log-normal diffusion, and its value at any future time $t>0$ is

$$
V_{t}=V_{0} \exp \left(-\frac{\sigma^{2}}{2} t+\sigma Z_{t}\right),
$$

\footnotetext{
${ }^{12}$ In this example there is another indirect effect of a lower long-term debt face value under the new distribution.
} 
where $Z_{t} \sim N(0, t)$, and the volatility $\sigma$ is a constant. Later we introduce state dependent volatilities. Without loss of generality we set the risk-free rate to be zero.

Following Merton (1974), the firm has a zero-coupon debt issue that matures at time $t$ with a face value $F_{t}$, and this is the firm's only debt. At time $t$, if the firm value $V_{t}$ is below $F_{t}$, debt holders take the defaulted firm to obtain $V_{t}$; otherwise, debt holders are repaid in full by $F_{t}$. Because $V_{t}$ follows a martingale, a shorter maturity of debt can equivalently be viewed as a debt to be repaid after a smaller amount of resolution of uncertainty about the firm's assets. Finally, recall that we rule out physical bankruptcy costs (i.e., the asset can be liquidated any time for its value $V_{t}$ ) and renegotiation of the debt in return for a changed investment decision.

As in our numerical examples before, we consider a single investment opportunity at date 0 modeled as a small scale expansion of existing assets. ${ }^{13}$ We examine the effect of debt maturity on debt overhang by varying $t$, the time horizon to a single debt maturity. To focus on maturity only, our analysis controls for the firm's initial leverage. More specifically, we adjust the face value $F_{t}$ to hold constant the time-0 market value of debt when we vary $t$.

\subsection{Stronger Short-Term Debt Overhang with Constant Volatility}

We first establish a benchmark result under constant volatility: Longer-term debt imposes stronger overhang on the time-0 investment for a given market leverage.

It is well-known in this setting that the payoff to equity holders will be reduced by debt overhang, which can be measured by the increase in the value of existing debt as a result of the scale expansion of $V_{0}$. How does debt maturity affect the amount of overhang?

Consider short-term (long-term) debt with face value $F_{1}\left(F_{2}\right)$, with maturity $m_{1}\left(m_{2}\right)$, where $m_{2}>m_{1}$. The standard Black-Scholes calculation gives the corresponding date- 0 debt value as

$$
D\left(V_{0} ; F_{i}, m_{i}\right)=V_{0}\left(1-N\left(d_{i}\right)\right)+F_{i} N\left(d_{i}-\sigma \sqrt{m_{i}}\right) \text {, where } d_{i} \equiv \frac{\ln \left(V_{0} / F_{i}\right)+0.5 \sigma^{2} m_{i}}{\sigma \sqrt{m_{i}}}, i=1,2
$$

\footnotetext{
${ }^{13}$ In the Black-Scholes-Merton setting with time-0 investment only, the firm's refinancing policy at time- $t$, i.e., whether the firm refinances existing debt with newly issued equity or newly issued debt, is irrelevant. Recall that the debt in consideration is the only debt that the firm has, which implies that the firm will refinance this debt at maturity date $t$ without existing claims (other than equity). Because the net present value of the date-0 investment undertaken will be known on date $t$, and future investors break even, equity holders will recover any gain from the investment, except those going to debt holders existing at date 0 .
} 
Debt overhang is measured by $D_{V} \equiv \partial D\left(V_{0} ; F, m\right) / \partial V_{0}$, which captures the impact of a change in firm value on the value of existing debt. We study the wedge between two debt overhangs:

$$
\Delta D_{V} \equiv D_{V}\left(V_{0} ; F_{1}, m_{1}\right)-D_{V}\left(V_{0} ; F_{2}, m_{2}\right),
$$

where face values $F_{2}>F_{1}$ are chosen to hold constant the initial firm leverage:

$$
D\left(V_{0} ; F_{1}, m_{1}\right)-D\left(V_{0} ; F_{2}, m_{2}\right)=0
$$

Proposition 1 formally states that $\Delta D_{V}$ in Eq. (1) is negative. Intuitively, given the same date-0 market debt value, shorter-term debt always gains less from any marginal increase of the time-0 assets-in-place $V_{0}$, resulting in better equity holders’ investment incentives.

Proposition 1. Under the Black-Scholes-Merton setting, we have $D_{V}\left(V_{0} ; F_{1}, m_{1}\right)<D_{V}\left(V_{0} ; F_{2}, m_{2}\right)$ whenever $D\left(V_{0} ; F_{1}, m_{1}\right)=D\left(V_{0} ; F_{2}, m_{2}\right)$. This implies that for a given initial debt market value, long-term debt imposes stronger overhang than short-term debt. ${ }^{14}$

Both the example in Section 2.3 and the Black-Scholes-Merton setting in Proposition 1 have state-independent volatility, i.e., uncertainty resolves at the same rate in good and bad states. The next subsection relaxes this assumption.

\subsection{Stronger Short-Term Overhang with State-Dependent Volatility}

Recall that in the example in Section 2.5, even with a single initial investment, conditional volatilities that increase in bad states can reverse the result that shorter-term debt imposes less overhang. Following this idea, we now show that a state-dependent volatility (more specifically, higher volatility given low assets-in-place state) in the Black-Scholes-Merton setting can lead to a stronger short-term debt overhang.

Consider the following simple modification of the Black-Scholes-Merton model, where short-term debt (long-term debt) will mature at $m_{1}=1\left(m_{2}=2\right)$. Suppose that the firm's assetsin-place value at the end of period 2 is $V_{2}=V_{0} \exp \left(\tilde{z}_{1}-0.5 \sigma_{1}^{2}+\tilde{z}_{2}-0.5{\widetilde{\sigma_{2}^{2}}}^{2}\right.$, where $\tilde{z}_{1}$ and $\tilde{z}_{2}$ have zero mean and follow the normal distribution with variances $\sigma_{1}^{2}$ and $\widetilde{\sigma_{2}^{2}}$, respectively. Thus, the assets-in-place value on date 1 is $V_{1}=V_{0} \exp \left(\tilde{z}_{1}-0.5 \sigma_{1}^{2}\right)$

\footnotetext{
${ }^{14}$ All proofs are in the appendix.
} 
To introduce state-dependent volatility, we allow the volatility $\widetilde{\sigma_{2}^{2}}$ to be dependent on date 1 assets-in-place $\tilde{z}_{1}$. Particularly, for some constant $Q$ we set

$$
\tilde{\sigma}_{2}= \begin{cases}\sigma_{L} & \text { when } \tilde{z}_{1}>Q \\ \sigma_{H} & \text { when } \tilde{z}_{1} \leq Q\end{cases}
$$

where $\sigma_{L} \leq \sigma_{H}$. This formulation implies that the asset volatility is higher in low value states (or, a negatively skewed distribution). In fact, this pattern can be generated by the existence of volatility that is not scaled with the asset value. ${ }^{15}$ It is also a natural result when the borrower's assets are debt contracts, for example a bank, where volatility falls in good states when debt assets become default free.

We set the long-term debt face value $F_{2}=V_{0} \exp \left(Q-0.5 \sigma_{1}^{2}\right)$, so that the contingent volatility is lower (higher) for regions of $V_{1}$ being above (below) $F_{2}$. We have the following proposition.

Proposition 2. We adjust $F_{1}$ such that $D\left(V_{0} ; F_{1}, 1\right)=D\left(V_{0} ; F_{2}, 2\right)$, and suppose that $\varepsilon>0$ is sufficiently small.

Example 1. If $\sigma_{L}=\sigma_{H}=\varepsilon>0$, i.e., without contingent volatility, long-term debt imposes stronger overhang than short-term debt;

Example 2. If $\sigma_{H}=\varepsilon>0=\sigma_{L}$, i.e., with contingent volatility, short-term debt imposes stronger overhang than long-term debt.

With two contrasting examples, Proposition 2 shows that the conditional volatility could lead to stronger short-term debt overhang for date-0 investment. In example 2, the asset displays state-contingent $\tilde{Z}_{2}$ volatility, a pattern that is in sharp contrast to example 1 with constant $\tilde{Z}_{2}$ volatility (which is a special case of Proposition 1). The intuition is similar to that which we provide in Section 2.5. For short-term debt that is refinanced at date 1, whether the volatility of $\tilde{Z}_{2}$ is contingent or not does not affect its overhang. In contrast, for long-term debt, the volatility of $\tilde{Z}_{2}$ matters. To see this, after the bad realization $\tilde{z}_{1}=Q-\eta$, the risk of $\tilde{Z}_{2}$ reduces overhang (as equity holders can recover some investment benefits), and this force is present in both cases with contingent and constant volatilities (the same volatility $\sigma_{H}=\varepsilon$ ). However, after the good

\footnotetext{
${ }^{15}$ For instance, consider randomness in the fixed cost; then a fixed absolute volatility becomes a larger percentage of volatility when asset values are decreased.
} 
realization $\tilde{z}_{1}=Q+\eta$, the case of contingent volatility has a lower long-term debt overhang. It is because with contingent volatility $\sigma_{L}=0$, the date-2 firm value $V_{2}$ stays constant at $V_{1}=V_{0} \exp \left(Q+\eta-0.5 \sigma_{1}^{2}\right)$ which is above $F_{2}=V_{0} \exp \left(Q-0.5 \sigma_{1}^{2}\right)$, hence zero overhang without future default; but with constant volatility $\sigma_{L}=\varepsilon$ the firm value may deteriorate at date 2, leading to potential overhang. These comparisons result in a stronger short-term debt overhang in Proposition 2.

Proposition 2 illustrates how state-dependent volatility (higher volatility in worse states) in the Black-Scholes-Merton setting could lead to stronger shorter-term debt overhang. However, the existence of state-dependent volatility is not sufficient for stronger shorter-term overhang. What is general and shown in the proof of Proposition 2 is that this state-dependent volatility reduces the difference between long-term and short-term overhang. Moreover, Proposition 2 demonstrates that this effect can be sufficiently strong to overturn the positive long-short overhang wedge established in Proposition 1.

\subsection{Debt Maturity, State-Contingent Overhang, and Conditional Volatility}

In this subsection we offer another insightful way to understand the role of conditional volatility. As suggested by the numerical example in Section 2.4, the relative severity of longand short-term overhang depends on the future state of firm value, and longer-term debt imposes more (less) overhang in good (bad) states. The average of these future state-dependent overhang severities determines the time-0 investment incentives, and Proposition 1 shows that in the Black-Scholes-Merton constant volatility setting, once controlling the time-0 market debt value, the average long-term debt overhang always exceeds the average short-term overhang.

Conditional volatility is a way to twist the state-dependent overhang to potentially deliver a greater date- 0 average short-term overhang, thus reversing Proposition 1 . In the Black-ScholesMerton setting the effective debt maturity is inversely related to the speed of resolution of uncertainty, which is also asset volatility. From this perspective, the conditional volatility allows us to twist the effective debt maturities given different states. In Example 2 with contingent volatility in Proposition 2, at date-1 good states, the zero date-2 volatility implies no difference between long-term debt (that matures at date-2) and short-term debt (that matures at date-1). This minimizes the (positive) wedge: the excess of long-term over short-term overhang. In contrast, at date- 1 bad states, short- and long-term debts differ given the positive date-2 volatility, 
which preserves the negative wedge between long- and short-term overhang. In sum, higher conditional volatilities at lower assets-in-place states can reduce the positive excess of long-term overhang over short-term overhang in good times while preserving the negative difference in bad times. For the single initial investment, this increases date- 0 average overhang of short-term debt compared to long-term.

\section{Debt Overhang with Dynamic Investment}

To examine the long horizon effects of debt maturity, we need a tractable framework with dynamic investment opportunities that goes beyond the Black-Scholes-Merton model. We have two goals for this dynamic analysis. First, we would like to study debt overhang for a firm with stochastic values of assets-in-places and with access to future investment opportunities. This will generalize the examples in Section 2.4 where investment is made after the realization of news about asset values. Second, all of our previous examples and Black-Scholes-Merton models have had refinancing (if any) occurring at a time where there is no other existing debt outstanding. When debt is refinanced, the incentives to refinance or default are influenced by the maturity of existing outstanding debt on that date, which is another form of debt overhang. As we show, these two crucial features (which are missing from static models) lead to interesting implications about short-term debt overhang.

\subsection{The Setting and Valuations}

Models with multiple debt issues and dynamics in the value of assets are difficult to analyze, and the most tractable existing framework is based on Leland (1994b, 1998) which takes as fixed parameters both the frequency of refinancing and the total amount of promised repayments of debt. There, equity holders always have access to funds to cover the investment costs or losses at refinancing. Default then occurs only when their incentive to inject more funding is insufficient. This allows us to eliminate issues of limited liquidity (e.g., Diamond, 1991) and focus instead on debt overhang by examining the equity holders' incentive to inject funds into the firm.

\subsubsection{Firm assets}

Consider a firm that generates cash flows at a rate of $X_{t}$. We interpret $X_{t}$ as assets-in-place which evolve as follows:

$$
\frac{d X_{t}}{X_{t}}=\tilde{i}_{t} d t+\sigma d Z_{t} .
$$


Here, $\sigma$ is the constant volatility, and $\left\{Z_{t}: 0 \leq t<\infty\right\}$ is the standard Brownian motion. Differing from standard Leland settings, in Eq. (2) the growth rate $\tilde{i}_{t}$ is the endogenous investment decision controlled by equity holders. For simplicity, we assume that $\tilde{i} \in\{0, i\}$ takes a binary value, i.e., equity holders can decide to invest or not. The investment cost is modeled as $\lambda X_{t} i_{t} d t$ because the investment benefit scales with $X_{t}$ as well.

We assume a constant interest (discount) rate $r>0$ in this infinite horizon model. If equity holders always invest, then the present value of the firm, given the current value of assets-inplace $X_{t}$, is

$$
\mathbb{E}_{t}\left[\int_{t}^{\infty} e^{-r(s-t)}\left(X_{s}-\lambda i X_{s}\right) d s\right]=\frac{1-\lambda i}{r-i} X_{t} .
$$

Comparing this value to the value $X_{t} / r$ without investment at all, we assume that $\lambda r<1$ which ensures that investment at every instant would maximize the total value of the firm.

Denote the investment policy by $i(X)$ which depends on current assets-in-place $X$. In Proposition 3 we will show that in equilibrium equity holders use a simple threshold policy, i.e., invest whenever the value of assets-in-place exceeds a critical level $X_{i}$ :

$$
i(X)=\left\{\begin{array}{ll}
i & X \geq X_{i} \\
0 & X<X_{i}
\end{array} .\right.
$$

As mentioned in Section 2.1, investment can be only taken by equity holders, and future investment opportunities are lost when debt holders take over the firm from bankruptcy. This leads to an endogenous cost of financial distress. Unlike Leland's models, we impose no other exogenous costs of financial distress.

\subsubsection{Stationary debt structure}

The firm has one unit of debt with a constant aggregate principal face value of $P$. As in Leland (1994b, 1998), we take a simple refinancing policy which governs the firm's maturity structure. Under this framework with refinancing frequency $f$, at each instant a constant fraction of debt, $f d t$, becomes due and must be refinanced to keep the amount of total debt outstanding 
constant. This isolates the effect of maturity from changes in the amount of debt. ${ }^{16}$ This stationary debt structure describes a firm which smoothes out interest and principal payments to avoid spikes in refinancing activity. One immediate application of the constant refinancing rate is analysis of borrowers who for some exogenous reason have a particular debt maturity. For example, banks issue short-term deposits and have a very short debt maturity. More generally, the stationary debt structure is assumed for tractability, but is a sensible place to start. For detailed discussion about this refinancing policy, see Section 4.6.

One can show that the average debt maturity is $m \equiv 1 / f$. The higher the rollover frequency $f$, the shorter the debt maturity. To the extreme, if $f$ goes to infinity (so $m$ goes to zero), then the debt represents zero maturity demandable debt that matures immediately after the issuance.

The advantage of this setting is that, because each bond is retired exponentially, at any point of time the firm's existing bonds--including those just newly issued--are identical. Besides tractability, we adopt this framework because the overall refinancing rate is the most relevant variable to characterize a firm's debt maturity structure, and we treat this refinancing rate as a parameter. For understanding overhang, this is a reasonable treatment because the refinancing rate is essentially the frequency of repricing, and repricing to reflect the benefits of new investment is central to the equity holders' incentives to invest. Thus, this framework preserves the key difference between long- and short-term debt in regard to overhang due to wealth transfer to debt holders. Interestingly, in addition to the usual positive force of repricing to reduce overhang on investment, we will see another offsetting effect where shorter-term debt leads equity to default earlier in bad times, which exacerbates overhang. The latter effect is closely related to rolling over debt, to which we turn next.

\subsubsection{Rolling over debt}

The market value of the firm's debt is denoted by $D\left(X_{t}\right)$. In refinancing, the firm issues $(1 / m) d t$ units of new bonds to receive total proceeds of $\left(D\left(X_{t}\right) / m\right) d t$, paying $(P / m) d t$ to retire maturing bonds. The market price of newly issued bonds fluctuates with assets-in-place $X_{t}$, leading to net payments to bond holders which we refer to as rollover gains/losses of

\footnotetext{
16 “Debt retirement” in this fashion is similar to a sinking fund that continuously buys back debt at par with a constant rate of repayment.
} 
$\frac{1}{m}\left[D\left(X_{t}\right)-P\right] d t{ }^{17}$ Equity holders are the residual claimants of the rollover gains or losses: any gain will be immediately paid out to equity holders and any loss will be paid off by issuing more equity at its market price. Thus, the net cash flow to equity holders is

$$
X_{t} d t-\lambda X_{t} \tilde{i}_{t} d t+\frac{1}{m}\left[D\left(X_{t}\right)-P\right] d t
$$

The first term is the firm's cash flows, the second term is the investment cost, and the third term is the rollover loss. As emphasized by He and Xiong (2012), when the assets-in-place $X_{t}$ deteriorate in value, equity holders absorb the rollover loss by issuing additional equity to prevent bankruptcy, and this loss is amplified by the rollover frequency $f=1 / m$. Equity holders are willing to inject cash to repay the maturing debt holders as long as the option value of keeping the firm alive (and hence choosing to default later) justifies the expected rollover losses. This leads to default when the equity value drops to zero, which occurs when the firm's assetsin-place $X_{t}$ drops to an endogenously determined threshold $X_{B}$.

\subsubsection{Valuations and optimal policies}

The debt value satisfies the following equation:

$$
r D(X)=i(X) D^{\prime}(X)+\frac{\sigma^{2}}{2} D^{\prime \prime}(X)+\frac{1}{m}(P-D(X)) .
$$

The left-hand side is the required return for the debt, which equals the expected increment in the debt value on the right-hand side. The first two terms capture the fluctuation in $X_{t}$ in Eq (2). The third term is the change of the debt value due to retirement: a $(1 / \mathrm{m}) d t$ fraction of debt matures, with the valuation change being the principal payment $P$ minus the bond value before retiring.

We need boundary conditions to solve Eq.(5). Firms with extremely profitable assets-inplace $X=\infty$ never default and the default-free debt value is $p \equiv P /(1+m r)$. From now on we treat the default-free debt value $p$ as the primitive parameter (instead of the stated principal value $P$ ). On the other hand, equity defaults when $X=X_{B}$, and debt holders receive the firm with a

\footnotetext{
${ }^{17}$ Because of zero-coupon debt, discounting implies the firm always incurs rollover losses. Rollover gains could occur if we instead assumed a bond issued at par by setting a coupon rate higher than $r$. Whether rollover gains are possible or not is not essential to our analysis. As shown in He and Xiong (2012), the key is that increased rollover losses for lower values of the assets-in-place increase equity holders' incentive to default.
} 
value of $D\left(X_{B}\right)=X_{B} / r$ without future investment (there is no exogenous bankruptcy cost). One can formally show that $p>X_{B} / r$, i.e., on the date of default there is a loss to debt holders. ${ }^{18}$

Equity holders' value $E(X)$ satisfies the following equation:

$$
r E(X)=\max _{i_{t} \in\{0, i\}} X+i_{t} X E^{\prime}(X)+\frac{1}{2} \sigma^{2} X^{2} E^{\prime \prime}(X)-\lambda i_{t} X-\frac{1}{m}(P-D(X))
$$

We have omitted the optimal default policy here; equity holders default at some endogenous level $X_{B}$ and receive zero. The optimization in Eq. (6) with respect to $i_{t}$ leads to an investment policy in Eq. (4). The next proposition verifies the optimality of the threshold investment strategy, and gives equity and debt values as solutions to Eq. (5) and Eq. (6), respectively.

Proposition 3. There exists a unique $X_{i}$ with $E^{\prime}\left(X_{i}\right)=\lambda$ so that the optimal investment policy is given by Eq. (4). Given $X_{i}$ and $X_{B}$ the equity value is

$$
E(X)=\left\{\begin{array}{cc}
\frac{X(1-\lambda i)}{r-i}-p+B_{1} X^{-\gamma_{3}}-A_{1} X^{-\gamma_{1}} & X \geq X_{i} \\
\frac{X}{r}-p+B_{2} X^{-\gamma_{4}}+B_{3} X^{\delta_{4}}-A_{2} X^{-\gamma_{2}}-A_{3} X^{\delta_{2}} & X_{B}<X<X_{i}
\end{array},\right.
$$

and

$$
D(X)=\left\{\begin{array}{cc}
p+A_{1} X^{-\gamma_{1}} & \text { if } X \geq X_{i} \\
p+A_{2} X^{-\gamma_{2}}+A_{3} X^{\delta_{2}} & \text { if } X_{B}<X<X_{i}
\end{array}\right.
$$

where constants $\gamma_{1}, \gamma_{2}, \gamma_{3}, \gamma_{4}, \delta_{2}, \delta_{4}, A_{1}, A_{2}, A_{3}, B_{1}, B_{2}$, and $B_{3}$ are given in the Appendix.

The expression for equity value is intuitive. When the firm invests $X \geq X_{i}$, the equity value is the firm value that would prevail if the firm always invested, $X(1-\lambda i) /(r-i)$ in Eq. (3), minus the default-free debt value $p$, with the adjustment for potential future default and stopping investment (at least temporarily). Outside the investment region $X_{B}<X<X_{i}$, the equity value is the firm value without investment $X / r$ minus the default-free debt value $p$, taking into account both potential future default and coming back to the investment region.

\footnotetext{
${ }^{18}$ This can be seen by a standard real option argument. Suppose that $X_{B} \geq r p$; then $D\left(X_{B}\right)=p$ and the debt is riskless. With the option to default, equity holders must incur strictly negative cash flows at $X_{B}$. From Eq. (6), since equity holders can set $\tilde{i}=0$, at $X_{B}$ the cash flow for equity is at least $X_{B}-(P-p) / m=X_{B}-r p>0$, contradiction.
} 
Finally, the endogenous investment threshold $X_{i}$ satisfies $E^{\prime}\left(X_{i}\right)=\lambda$, and the endogenous default boundary $X_{B}$ satisfies the smooth-pasting condition $E^{\prime}\left(X_{B}\right)=0$. The detailed equations and steps in solving for these two endogenous variables are given in the Appendix.

\subsection{Optimal Debt Maturity}

Recall that the example in Section 2.4 illustrated the following idea. For future investment opportunities, short-term debt hurts the firm's incentives to invest especially in bad times. However, long-term debt imposes a less state-contingent overhang, and reduces the firm's
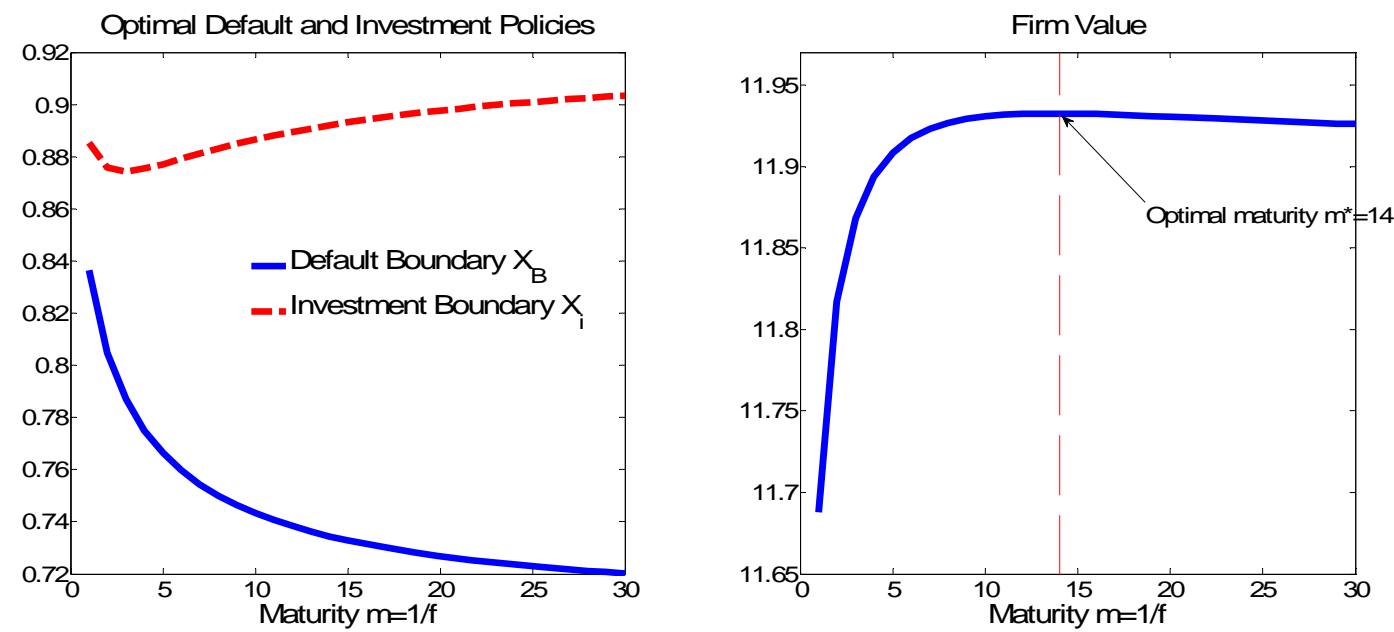

Figure 2: Optimal default policy (solid line) and investment policy (dashed line) and firm values for different debt maturities. The parameters are $r=10 \%, \sigma=15 \%, i=7 \%, \lambda=9, X_{0}=1$, and $D_{0}=10$.

investment incentives especially in good times (relative to short-term debt). As we illustrate now, this trade-off generally leads to an interior optimal maturity choice.

We choose $r=10 \%, \sigma=15 \%, i=7 \%$, and $\lambda=9$. We normalize the date- 0 assets-in-place to $X_{0}=1$, and set the target date- 0 debt value $D_{0}=10$. The left panel of Figure 2 graphs the optimal investment and default policies, and the right panel graphs the date- 0 firm value; both are plotted against debt maturity $m$. As before, to fix date-0 debt value $D_{0}$, when varying maturity $m$ we search for the default-free debt value $p$ so that $D_{0}=10$ always. ${ }^{19}$

In this model, because shorter-term debt requires equity holders to absorb greater rollover losses (incurring higher financing costs) once the firm's assets-in-place deteriorate, equity holders default earlier as they refuse to subsidize debt holders, a symptom of debt overhang. This

\footnotetext{
${ }^{19}$ Though not reported, in our example $p$ is increasing in debt maturity to compensate for the greater default risk associated with longer-term debt.
} 
result can also be seen by observing that, because shorter-term debt does not share as much risk, it leads to more volatile equity value and hence equity holders' default option falls "into the money" more often. Graphically, in the left panel of Figure 2 we observe that default boundary $X_{B}$ rises (hence earlier default) for shorter debt maturity $m$. As default destroys future investment opportunities, earlier default caused by short-term overhang hurts the firm value.

Now focus on investment policy. In the left panel of Figure 2, we find that the investment threshold $X_{i}$ first decreases with debt maturity for $m$ that is below about 2, then increases with debt maturity afterwards. We will devote Section 4.4 to discuss the range of very short maturity debt (i.e., $m$ below about 2 ) where shorter maturity reduces investment incentives. In this section, we only focus on the increasing region where shorter debt maturity improves investment incentives.

For debt maturity $m$ being above about 2 , equity holders are more reluctant to invest (a higher threshold $X_{i}$ ) facing debt with longer maturity (a greater $m$ ). Relative to short-term debt, although the long-term debt holders--due to less frequent repricing--share more losses with equity holders when the assets-in-place deteriorate, they also share more gains given good news. Consequently, as more investment benefit goes to debt holders (increased overhang), equity holders will set a higher investment threshold $X_{i}$ with longer-term debt.

The combination of these two forces (one on default policy, and the other on investment policy) leads to an interior optimal maturity choice $\left(m^{*}=14\right)$ that maximizes the initial firm value, as shown in the right panel of Figure 2. To further illustrate the mechanism, Figure 3 plots the marginal impact of the firm's assets-in-place on equity value, i.e., $E^{\prime}(X)$ for $m=5$ (thin solid line), $m=14$ (thick solid line) and $m=30$ (thin dashed line). We can directly compare the equity holders' investment incentive $E^{\prime}(X)$ to the investment cost $\lambda$ (flat dotted line). Firms with shorter debt maturity $m=5$ have the steepest $E^{\prime}(X)$ curve: they invest early once $E^{\prime}(X)$ crosses $\lambda$, but also default early when $E^{\prime}(X)$ hits zero. As shown, the flatter equity holders' investment incentive $E^{\prime}(X)$ under a longer debt maturity $m=30$ gives the opposite effect: the firm invests late and defaults late. The curve $m=14$ balances these two forces and delivers the highest firm value. 


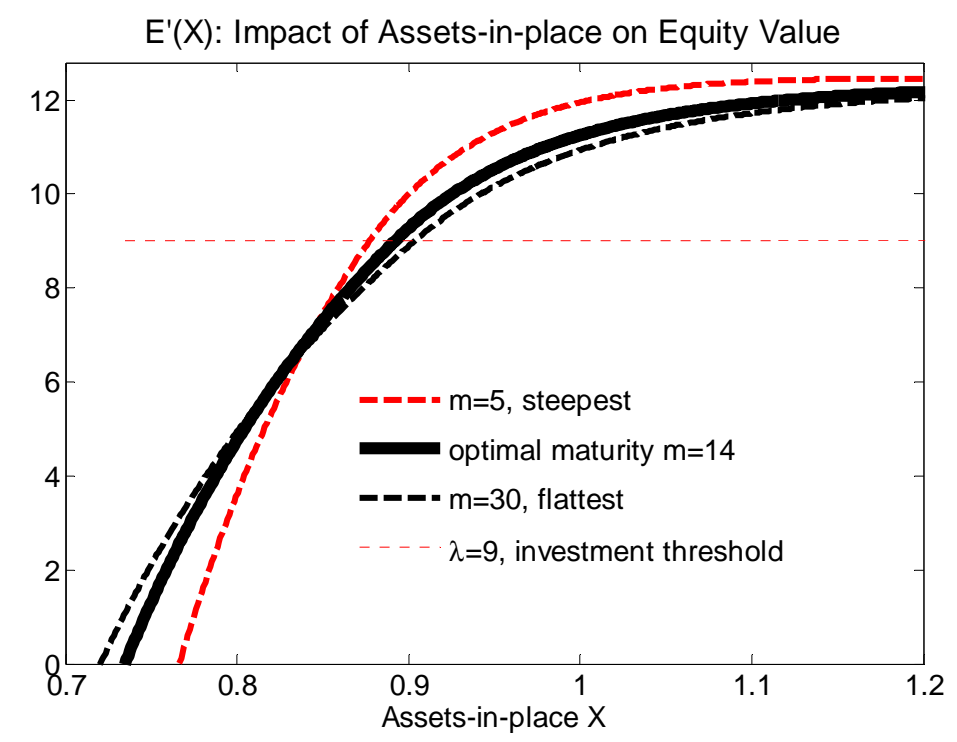

Figure 3: The impact of assets-in-place on equity value $E^{\prime}(X)$ for debt maturities $m=5$ (thin solid line), $m=14$ (thick solid line), and $m=30$ (thin dashed line). The investment cost $\lambda=9$ is also plotted (flat dotted line) so that the investment threshold $X_{i}$ satisfies $E^{\prime \prime}\left(X_{i}\right)=\lambda$. The parameters are $\mathrm{r}=10 \%, \sigma=15 \%, \mathrm{i}=7 \%, \lambda=9, \mathrm{X}_{0}=1$, and $\mathrm{D}_{0}=10$.

Underlying the pattern of "the shorter the debt maturity, the steeper the equity holders' investment incentives" is the insensitivity of short-term debt value with respect to the firm value, due to more frequent repricing. This translates to a greater volatility of debt overhang of shortterm debt, a result consistent with the example in Section 2.4. As shown in Figure 3, equity holders with $m=5$ have lower $E^{\prime}(X)$ for low values of assets-in-place and therefore default earlier, but also have higher $E^{\prime}(X)$ for high values of assets-in-place which fosters efficient investment. Hence, although not sharing gains makes short-term debt better at preserving equity's incentive to invest in good times, not sharing losses in bad times pushes equity holders to default, eliminating future investment opportunities. In contrast, equity holders with $m=30$ have worse investment incentives in good times, but they are also willing to hold on longer to retain future investment opportunities, since long-term debt shares more losses in bad times.

Before we move on to the next subsection, recall that in the left panel of Figure 2, for very short maturity (below about 2 years), both the investment and default thresholds decrease with debt maturity. In this range, an even shorter-term debt presents a double evil--firms are not only more likely to default but also less likely to invest. This result is related to the assumption of inter-temporally linked investment, a topic that we discuss in Section 4.4. 


\subsection{State-Dependent Investment Opportunities}

The discussion of the higher volatility of investment with shorter-term debt suggests a role of state-dependence of investment opportunities. Because short-term debt is better at preserving equity holders' investment incentives in good times, a firm with sufficiently good investment opportunities in good times should use shorter-term debt for better investment incentives. This section further explores this idea.

\subsubsection{Fixed investment cost and optimal policies}

Keep the same binary investment technology (either invest or not) as in Section 4.1, but modify the investment cost as a combination of fixed cost part $\rho$ and variable cost part $\Delta$ :

$$
\lambda\left(X_{t} ; \rho, \Delta\right)=\rho+\Delta \lambda i X_{t} .
$$

We can broadly interpret the case of $\rho<0$ as fixed investment benefit, as by investing the firm receives $-\rho$ as a flow benefit. When $\rho=0$ and $\Delta=1$ we are back to our base model studied above with a pure variable cost. To isolate state-dependence of investment opportunities from overall profitability, we posit a cost structure so that on average the firm value remains unchanged; for instance, $\rho>0$ and $\Delta<1$.

The structure in (7) allows us to use the fixed investment cost part $\rho>0$ to proxy for the state-dependence of investment opportunities. To show this, we demonstrate that a higher $\rho$ implies a higher correlation between investment opportunities and assets-in-place. Recall that we always keep the investment benefit to be purely variable, i.e., $X_{t}$ grows at a rate of $i$ by investing. Therefore, the net present value (NPV), of investing always from now on, is (using the similar calculation as in Eq. (3))

$$
\underset{\text { Investment benefit }}{\left(\frac{X}{r-i}-\frac{X}{r}\right)_{\text {Investment cost }}}-\left(\frac{\Delta \lambda i X}{r-i}+\frac{\rho}{r}\right)=\frac{i(1-\Delta \lambda)}{r(r-i)} X-\frac{\rho}{r} .
$$

On the left hand side, the first parenthesis is the increment of the firm present value by investing always, and the second parenthesis is the present value of total investment cost. The difference is the NPV of investment (always) given on the right hand side.

Eq. (8) suggests that, relative to the base case of $\rho=0$ and $\Delta=1$, the case of $\rho>0$ and $\Delta<1$ makes the investment NPV more sensitive to $X_{t}$, i.e., a higher correlation between investment opportunities and assets-in-place. The similar but exactly opposite reasoning implies that the 

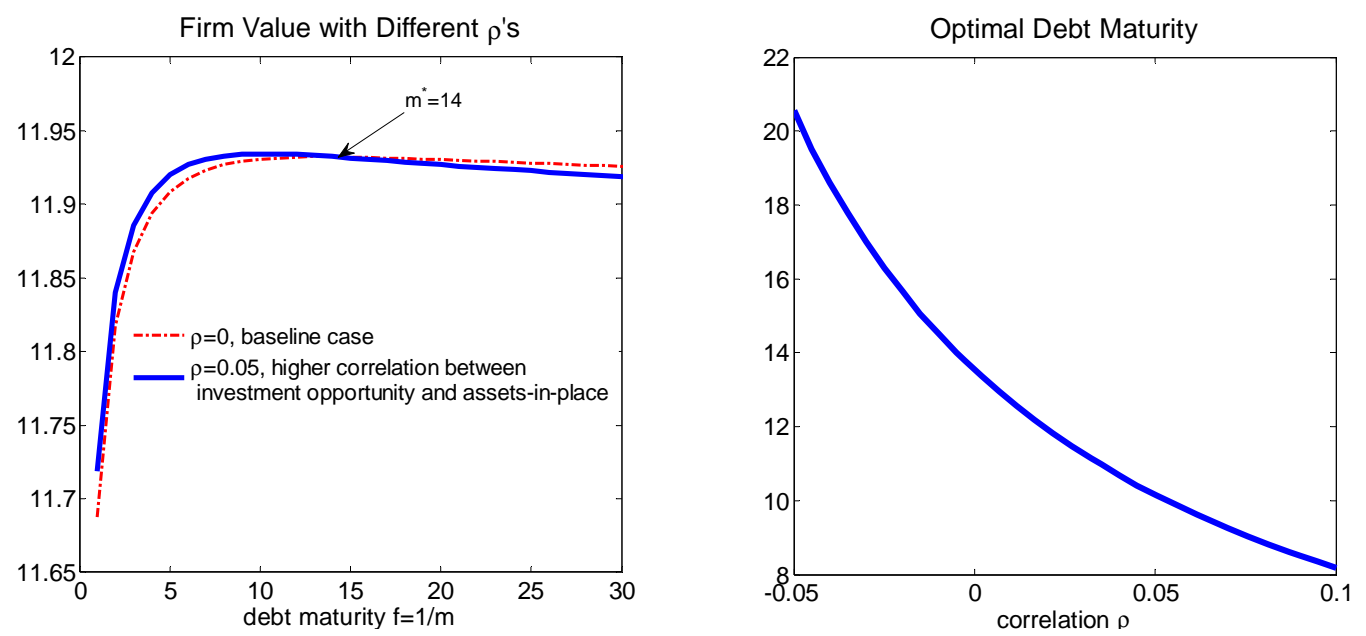

Figure 4: Optimal debt maturity as a function of state-dependence of investment opportunities. The left panel plots the firm value against debt maturity, for both the baseline case $(\rho=0$, dashed line) and the case with a higher correlation between investment opportunities and assets-in-place $(\rho=0.05$, solid line). The right panel plots the optimal debt maturity as a function of $\rho$. The parameters are $r=10 \%, \sigma=15 \%, i=7 \%, \lambda=9, X_{0}=1$, and $D_{0}=10$.

firm with $\rho>0$ and $\Delta<1$ has worse investment opportunities for lower assets-in-place. ${ }^{20}$ Hence, from now on we refer to $\rho$ as the measure of correlation between firm's assets-in-place and investment opportunities. The higher the $\rho$, the better the investment opportunities in good times. In the Appendix we give the valuations and optimal policies for this extension.

\subsubsection{Optimal debt maturity and state-dependent investment opportunities}

The insight developed in Section 4.2 suggests that the firm should use shorter-term debt if its investment opportunities are better for higher values of the assets-in-place, i.e., a higher $\rho$. The logic is simple. In Figure 3 we have shown that shorter-term debt leads to lower overhang for higher values of assets-in-place. Therefore, it is particularly good at motivating equity holders to invest in good times, if indeed the firm has good investment opportunities around that time.

To illustrate this point, we start with the base model with a pure variable cost (i.e., $\rho=0$ and $\Delta=1$ ), and find the optimal maturity $m^{*}$ which achieves the highest firm value $V^{*}$. We then consider a positive $\rho>0$, and control the total firm value by adjusting downward the variable cost part $\Delta$ appropriately. Call the resulting variable cost $\Delta_{\rho}$. As shown in the left panel of Figure 4, this requires that the new firm value (as a function of debt maturity $m$, the solid line) under the cost structure $\left(\Delta_{\rho}, \rho\right)$ crosses the baseline firm value curve (the dashed line) at $m^{*}$.

\footnotetext{
${ }^{20}$ With only a fixed cost, even an all-equity firm stops investing when the variable investment benefit goes below the fixed cost for sufficiently low assets-in-place (e.g, for $X_{t}$ close to zero).
} 
We are interested in the optimal maturity that maximizes the firm value under $\left(\Delta_{\rho}, \rho\right)$ with $\rho>0$. Because the firm value has a negative slope at the original optimal maturity $m^{*}$ in the left panel of Figure 4, the optimal maturity with a higher $\rho>0$ must be shorter than $m^{*}$ (with $\rho=0$ ).

Denote the resulting optimal maturity, as a function of $\rho$, by $m^{*}(\rho)$. The procedure described above allows us to graph the optimal maturity $m^{*}(\rho)$ in the right panel of Figure 4. As expected, when the firm has greater investment opportunities for high assets-in-place, the longerterm debt overhang hurts the firm value more severely, and as a result the firm should adjust its optimal debt maturity toward shorter-term.

This result has important empirical implications. The debt of a growth firm should be shorter-term, only if we define a growth firm as one with substantial uncertainty about its investment opportunities and that the value of its existing investment projects is highly correlated with the value of new investment. In comparison, if future opportunities are known and current asset returns are not very informative about them, then for a given amount of leverage, the firm value is higher with longer-term debt. Firms with investment opportunities that are most important in bad times, such as mature firms where maintenance investment is needed to replace unexpectedly high depreciation and there is little learning about other aspects of profitability, will maximize value with even longer-term debt. This is very different from the idea that firms with substantial future investment opportunities should choose shorter-term debt.

\subsection{Short-term Debt Overhang and Inter-Temporally Linked Investment}

At the end of Section 4.2 we pointed out that, in the left panel of Figure 2, short-term debt may be doubly evil: for maturity below 2 , firms with shorter-term debt may default earlier and be less likely to invest.

To understand this result, we stress one important property of our investment technology. In our dynamic setting laid out in Section 4.1.1, Eq. (2) implies that investment benefits are intertemporally linked. Consider the hypothetical situation that starting from next period the firm may lose its future investment opportunities with an exogenous probability $\pi \in[0,1]$, but will keep investing in the future with probability $1-\pi$. One can interpret $\pi$ as the firm's exogenous default probability. 
Investment today improves the current value of assets-in-place $X_{t}$ to $X_{t}(1+i d t)$ at the end of today; but what about the market value of assets-in-place? Because the value is $\frac{1-\lambda i}{r-i} X_{t}(1+i d t)$ with future investment while only $X_{t}(1+i d t) / r$ otherwise (recall Eq. (3)), the firm value at the end of today, given the exogenous default probability $\pi$, is

$$
\left[\pi \frac{1}{r}+(1-\pi) \frac{1-\lambda i}{r-i}\right] X_{t}(1+i d t) \text {. }
$$

Importantly, this value is decreasing in the default probability $\pi$. In our setting with log-normal structure, investment decisions at all periods enter the total firm value in a multiplicative fashion, and hence a high future investment policy boosts the equity holders' investment incentive today. The positively connected investment incentives across periods are natural, and particularly relevant in situations with staged investments.

In our model, the probability of future default $\pi$ is endogenous, and moreover, increasing in the equity holders' default threshold $X_{B}$. In the left panel of Figure 2, the ultra-short debt maturity leads equity holders to set a high default threshold $X_{B}$. Hence, current investment that will not be made to grow in the future becomes less profitable. Put differently, short-term debt and associated default eliminates future firm growth, which reduces the total payoff of current investment.

In Section 4.2 we have seen another opposite force, through which short-term debt improves equity holders' investment incentives due to more frequent repricing. Which force prevails depends on parameters. In the following proposition, we consider the limiting case where debt approaches demandable debt with zero maturity, and provide a sufficient condition under which the effect of eliminating future growth dominates.

As we point out in the Appendix, this sufficient condition always holds for low but positive investment cost, i.e., when $\lambda$ is sufficiently small. To see this, recall that $E^{\prime}\left(X_{i}\right)=\lambda$ while $E^{\prime}\left(X_{B}\right)=0$; hence $\lambda$ also captures the distance between investment and default. If this distance is close, then the effect of eliminating future growth dominates. By interpreting investments that should be made even when close to default as maintenance, this result essentially says that the shorter the debt maturity, the sooner the firm defaults, and the earlier the firm stops maintaining its assets. 
Proposition 4. Fix the date-0 market value of debt, and let debt maturity approach zero, i.e., $m \rightarrow 0$. We have the following results:

1. The default threshold $X_{B}$ converges torp .

2. When the primitive parameters satisfy the sufficient condition provided in the Appendix, the investment threshold $X_{i}$ is higher (making the firm likely to invest) for shorter debt maturity.

Proposition 4 establishes that debt overhang can exist even if firms issue a sequence of demandable debt contracts. Moreover, note that $X_{B} / r$ is the limit of firm value recovered at default by debt holders. Then, the first result in Proposition 4 says that for ultra-short-term debt, what debt holders recover in fact converges to the bonds' default-free value $p .{ }^{21}$ Therefore, these debt securities are almost riskless, but still impose overhang!

This result is interesting because, from the standard static model with a single investment opportunity, the logic of Myers (1977) implies that riskless debt leads to no overhang. However, in our dynamic model with inter-temporally dependent investment incentives, these almost riskfree debt securities impose strong overhang on equity holders. What drives this result?

The key mechanism is truncation of future investment opportunities in (future) bad states where the borrower chooses to default. Although lender losses are very small, this truncation hurts today's investment incentives of equity holders, given inter-temporally linked investment opportunities. In a static model, truncation is just payment default and necessarily implies risky debt. In a dynamic investment model, the significance of truncation of future investment is not related to whether debt holder losses are large. In fact, if anything, safer debt securities require more truncation, because to maintain safety debt holders should take over the firm at a higher value of assets-in-place. This is closely related to an extreme situation considered in Leland (1994), where the firm issues "protected debt" contracts whose holders can take over the firm whenever the firm value drops to the debt default-free value. By definition the debt is risk-free; however, one can show that equity holders' investment incentive right before default is $E^{\prime}(X)=1 / r$ (setting $\pi=1$ in Eq. (9)), which is below the first-best investment incentive $\frac{1-\lambda i}{r-i}$. As a result, protected riskless debt imposes overhang on inter-temporally linked investment.

\footnotetext{
${ }^{21}$ A similar result for ultra-short-debt is obtained by Leland and Toft (1996) in a model without investment opportunities but with bankruptcy costs.
} 


\subsection{What if the Investment Opportunity is Only in the Future?}

We have seen one drawback of short-term debt, i.e., inefficiently early default which eliminates future investment opportunities. To study this effect in isolation, we consider the simplified model without interim investment, i.e., $i=0$. Instead, the firm is waiting for a second stage for expansion, after which there is no future uncertainty. This expansion stage arrives as a Poisson event with intensity $\xi>0$ for equity holders to improve the assets-in-place $X_{t}$ to $\theta X_{t}$ at no cost, with $\theta>1$. We set the expansion cost to be zero so that equity holders are always willing to expand. This eliminates debt overhang in the expansion stage, and allows us to focus only on the debt overhang effect of default before the expansion stage.

Because default at $X_{B}$ eliminates the future investment opportunity, our modeling is isomorphic to a standard (exogenous) bankruptcy cost as in Leland (1994). Hence, maximizing the firm value is equivalent to inducing default as late as possible, i.e., minimizing the default boundary $X_{B}$. The derivation of debt value, equity value, and endogenous default boundary is standard (see Appendix). The endogenous default boundary can be derived in closed-form:

$$
X_{B}=\frac{r p \gamma_{5}(m)}{\gamma_{5}(m)-\gamma_{6}+\left(1+\gamma_{6}\right) \frac{r+\xi \theta}{r+\xi}}
$$

where $\gamma_{5}(m)$ and $\gamma_{6}$ are given in Eq. (13) in the Appendix. We further show that all else equal, $X_{B}$ is increasing in $p$, as equity holders default earlier for a greater debt burden; and all else equal, $X_{B}$ is decreasing in maturity $m$ so that shorter-term debt leads to earlier default. The next proposition gives a stronger result that $X_{B}$ is decreasing in maturity $m$, even if taking into account that the firm adjusts the promised debt value $p$ to control for leverage $D_{0}$.

Proposition 5. Fix target date-0 debt value. Equity holders always choose $p$ so that the date-0 debt value is increasing in $p$ (i.e., $\partial D_{0} / \partial p \geq 0$ ), and the default boundary $X_{B}$ is decreasing in $m$. Hence extremely long-term debt (i.e., $m=\infty$ ) is preferable.

Proposition 5 notes that at the optimum, the market value of debt always increases in the promised payment $p$. This excludes what might otherwise happen due to a debt "Laffer curve," where raising an already excessive promised payment reduces the debt value by inducing excessively earlier default. Equity holders who maximize date-0 firm value will avoid this wrong 
side of debt "Laffer curve," 22 and with the aid of this observation we are able to prove that $d X_{B} / d m<0$, i.e., equity holders default later with longer-term debt.

This result formalizes the intuition that "long-term debt is better at preserving firm's incentives to stay alive for future investment." Also, one can show that, in the similar spirit of Section 3 with immediate investment, if the investment opportunity is only present at date-0, then shorter-term debt is preferable in reducing overhang (the proof is upon request). These two extreme cases (one only with future investment, the other only with immediate investment) are the forces behind the trade-off shown in Section 4.2 for firms with interim investment opportunities.

\subsection{Discussion of a Changing Refinancing Policy}

Refinancing policy, which affects future overhang when issuing new debt, is one of the natural ingredients of an optimal debt maturity structure. Following Leland (1994b, 1998) and for tractability, we have performed our analysis based on a stationary debt structure with constant refinancing rate $f=1 / \mathrm{m}$. Because the option to default and repricing are the reasons that maturity influences debt overhang, this dynamic framework with stochastic values of assetsin-place captures important issues of how debt maturity influences the equity holders' incentives to invest over time. ${ }^{23}$ Moreover, our analysis applies to the situation where the firm's debt maturity structure is largely determined by other considerations (e.g., commercial banks with demand deposits).

What if firms have flexibility in adjusting their refinancing policies, instead of a constant refinancing policy? Determining a desirable policy with a variable debt maturity requires knowledge of the effects of a fixed maturity. A full analysis of the case of flexible refinancing policies is intractable using existing models and beyond the scope of this paper. ${ }^{24}$ Nevertheless,

\footnotetext{
${ }^{22}$ That is, there exists some default-free debt value $\bar{p}$ that produces a maximum market value of the date- 0 debt. Equity holders would never promise debt holders more than $\bar{p}$ because they could raise the same amount by promising them less and defaulting less (both of which increase the payoff of equity holders).

${ }^{23}$ The convenient feature of this setting is that looking forward the model is always identical, because the firm keeps the total amount of promised payments constant over time. What varies is the amount raised from this promise (and this leads to a time varying shortfall of funds which is larger when default risk is higher). In practice, this is primarily about units of measurement of default premia. Whether the default premia are represented by a larger shortfall or higher future promises is not responsible for our qualitative results.

${ }^{24}$ Existing studies of dynamic adjustments to leverage by firms with investment decisions assume that debt maturity is fixed. Moyen (2007) assumes that long-term debt can never adjust its future payments while short-term debt can and will always adjust to its optimal leverage. Titman and Tsyplakov (2007) follow Fischer, Heinkel, and Zechner (1989) to assume that a firm has to call back its entire outstanding debt whenever adjusting its capital structure. This
} 
we provide some discussion which may be helpful in understanding the robustness of our results to other refinancing policies.

\subsubsection{Robustness of state-contingent short-term debt overhang}

Our key result that short-term debt imposes more (less) overhang in bad (good) times should be qualitatively robust. Take our model, but suppose that the firm can freely set the refinancing rate $f$ for newly issued bonds as the assets-in-place value $X_{t}$ fluctuates. If this were possible, the firm could, as part of an explicit contract, adjust its debt maturity structure dynamically. For better investment/default incentives, we expect the refinancing rate $f$ for newly issued bonds to be increasing in the assets-in-place $X_{t},{ }^{25}$ so that the firm is targeting a move toward a shorter(longer-) term maturity structure when the value of assets-in-place is high (low) on average. Having said that, because the firm's assets-in-place fluctuates unexpectedly, and it takes time to fully adjust the firm's overall debt maturity, having short- (long-) term debt only in good (bad) times is not achievable. Moreover, the unexpected fluctuation of $X$ also implies that it is not optimal to take some extreme refinancing policies, say $f(X) \rightarrow 0$ for sufficiently low $X$. For this reason, the qualitative result that short-term debt imposes more (less) overhang in bad (good) times should remain in the more general model.

The above discussion suggests that debt with state-contingent maturities, especially bonds with automatically reset longer maturity in bad times and shorter maturity in good times, will be value-improving. In practice, we do observe this favorable state-contingency in the call feature of some long-term debt. ${ }^{26}$ Hence, firms with state independent future investment opportunities can improve investment incentives by using callable debt.

\subsubsection{Dilution issue when lengthening maturity in bad times}

Another important issue relates to dilution, such as transfers to other debt holders if equity holders were to choose to lengthen the maturity of new debt during bad times. Fixing the amount to be promised in the future, lengthening maturity today with existing debt in place increases today’s rollover losses to equity--simply because longer-term debt has a lower price than shorter-

(fairly strong) assumption is needed for tractability, by eliminating the chance to dilute existing debt, but may not be close to reality. The next section describes the importance of potential dilution.

${ }^{25}$ The refinancing rate of newly issued bonds may also depend on the maturity structure of the firm's exiting debt.

${ }^{26}$ Bodie and Taggart (1978) suggest that callable long-term debt can alleviate overhang. However, the authors still deem it as a puzzle why firms do not simply roll over short-term debt, which suggests that they do not realize that rolling over short-term debt may worsen overhang in some states. An earlier draft of our paper examined callable bonds and cash holdings (in a setting where managerial incentives were impaired by large cash holdings). 
term debt with the same face value. This also says that moving to longer maturity subsidizes existing soon-to-mature debt (by equity holders), as the policy gives existing debt holders effective seniority (i.e., the timing of receiving money back) relative to new incoming debt holders with longer maturity. ${ }^{27}$ The greater rollover losses in bad times in turn increases equity holders' default incentives for firms close to default, suggesting that dynamic policies of lengthening debt maturity and increasing rollover losses during bad times may be neither desirable nor in the ex-post interest of equity. In fact, for similar reasons, Titman and Tsyplakov (2007) find that equity holders may lack incentives to downward adjust firm leverage in bad times, although it is optimal to do so from the firm's perspective. See Diamond (1991), Diamond and Rajan (2001b) and Brunnermeier and Oehmke (2011) for models where debt becomes shorter-term in bad times with higher probability of default, which would further increase its overhang.

This argument that equity is averse to increasing debt maturity (at market prices) in bad times also lends support to the generality of the result that the policy of (a sequence of) ultra-short riskless debts imposes overhang on inter-temporally linked investment opportunities (see Section 4.4). However, without formal analysis, it is hard to be more precise about what will happen once we allow for flexible refinancing policies. We await future research on this topic.

\subsubsection{Flexibility of short-term debt}

Myers (1977) proposes that short-term debt could provide "for continuous and gradual renegotiation, in which the firm can in principal shift at any time back to all-equity financing.” This suggests that short-term debt offers flexibility for the firm to adjust its capital structure to avoid overhang. The benefit would be the shorter time for all or most debt to mature before either switching to all-equity, or negotiating with lenders for the benefits that equity holders obtain from injecting more cash. A related result is presented in a model by Brunnermeier and Yogo (2009) where the risk-free short-term debt allows the firm, at maturity, to switch to long-term debt financing, which reduces the risk of costly bankruptcy. This result holds because long-term debt defers bankruptcy and very long-term debt is not allowed in their model. Thus, continuing to issue short-term debt until the long term debt is

\footnotetext{
${ }^{27}$ This dilution is analyzed in Brunnermeier and Oehmke (2011) in a model with no investment after debt is issued, implying that long-term debt is efficient. Under certain conditions, equity holders prefer to issue a unit of new shortterm debt, which should be priced at a higher level than a unit of otherwise equal long-term debt. In essence, this new short-term debt dilutes the value of existing long-term debt holders.
} 
needed allows a longer effective maturity than the longest possible maturity available to the firm initially.

As examples of dynamic adjustment of maturity, both ideas rely on the assumption that there exists a time so that some news about investment opportunity or future default risk arrives before existing debt suffers any risk of default. Otherwise, as analyzed in our model with interim investment opportunities, short-term debt that is about to mature soon will impose overhang, which reduces the equity's incentives to invest or change to longer maturity--to the extreme, equity may even default. In addition, if the merit of short-term debt is to allow firms to get back to all-equity financing as quickly as possible, then the primitive reason for the firm to raise debt in the first place becomes important. Indeed, thorough calibration, Moyan (2007) finds that in a setting where firms raise short-term leverage to shelter taxes from improved profits before investment decisions, short-term debt leads to overhang as strong as that of long-term debt despite the fact that the firm can adjust short-term debt every period. What our analysis adds is that in an uncertain economy it can be very risky to rely on short-term debt to provide increased flexibility in future refinancing decisions.

\section{Conclusion}

Debt maturity influences investment incentives in a more nuanced way than suggested by existing analysis. By definition, investment incentives are weak (and debt overhang is severe) when very little of the return from investment accrues to equity. For a single immediate investment, we show in a Black-Scholes-Merton model that shorter maturity debt is less sensitive to increased firm value from a new investment. This provides an intuition why shorter-term debt may impose less overhang, because the difference between the total return from investment and the part accruing to equity is the change in the value of debt. When investment opportunities are present in the future, this intuition is incomplete. Less risk shared with existing shorter-term debt makes equity values and debt overhang more volatile, which affects future investment incentives.

We illustrate three ways in which shorter-term debt can impose stronger overhang. First, when volatility of firm value is sufficiently higher in bad times than good times, shorter-term debt can lead to higher overhang even for a single immediate investment decision taken just after the debt is issued. Second, in a dynamic setting with future investment opportunities, the reduction in equity value (and increased market leverage) due to the combination of bad times

and shorter-term debt is so large that equity holders' investment incentives suffer greatly, and 
they may choose to default earlier. Third, because shorter-term debt induces earlier future default and elimination of future growth, it hurts equity holders' incentives to invest (maintain) today when investment benefits are inter-temporally linked.

There is an interesting application combing all of our results. For reasons other than the effects on debt overhang, banks and other financial institutions issue short-term debt such as deposits, matching well with our exogenous constant refinancing structure, and fund debt contracts such as loans, implying high asset volatility in bad times. Our model then suggests that the effects of debt overhang in bad times will be extremely large for banks. This is for different reasons than the risk of runs and asset illiquidity leading to severe short-term debt overhang in Diamond and Rajan (2011). Adding our results to theirs suggests that the debt overhang problem for banks may be very severe.

The link between investment incentives and debt maturity is important for firms where future investments are important. Besides offering several testable implications for future empirical research, our paper suggests that managers who understand only one part of effect of debt maturity on investment incentives could make poor choices of debt maturity structure. 


\section{References}

Barclay, M., and C. Smith, Jr., 1995, The Maturity Structure of Corporate Debt, Journal of Finance 50, 609-632.

Benmelech, E., 2006, Managerial Entrenchment and Debt Maturity: Theory and Evidence, Working paper, Harvard University.

Billett, M., T. King, and D. Mauer, 2007, Growth Opportunities and the Choice of Leverage, Debt Maturity, and Covenants. Journal of Finance 62, 697-730.

Black, Fischer and Myron Scholes,1973, The Pricing of Options and Corporate Liabilities, Journal of Political Economy 81, 637-654.

Bodie, Z. and R. Taggart, 1978, Future Investment Opportunities and the Value of the Call Provisions on a Bond. Journal of Finance 33, 1187-1200.

Brunnermeier, M., and M. Oehmke, 2011, The Maturity Rat Race, forthcoming, Journal of Finance.

Brunnermeier, M. and M. Yogo, 2009, A Note on Liquidity Risk Management, American Economic Review: Papers and Proceedings 99, 578--583.

Calomiris, C., and C. Kahn, 1991, The Role of Demandable Debt in Structuring Optimal Banking Arrangements, American Economic Review 81, 497-513.

Diamond, Douglas W., 1991, Debt Maturity Structure and Liquidity Risk, Quarterly Journal of Economics 106, 709-737.

Diamond Douglas W., 1993, Seniority and maturity of debt contracts, Journal of Financial Economics 33, 341-368.

Diamond, D., and P. Dybvig, 1983, Bank Runs, Deposit Insurance, and Liquidity, Journal of Political Economy 91, 401-419.

Diamond, Douglas W., and R. Rajan, 2001a, Liquidity Risk, Liquidity Creation and Financial Fragility: A Theory of Banking, Journal of Political Economy 109, 287-327.

Diamond, Douglas W., and R. Rajan, 2001b, Banks, short-term debt and financial crises: theory, policy implications and applications, Carnegie-Rochester Conference Series on Public Policy 54, 37-71.

Fama, Eugene F., and Kenneth R. French, 2002, Testing Trade Off and Pecking Order Predictions About Dividends and Debt, Review of Financial Studies 15,1-33.

Fischer, E., R. Heinkel, and J. Zechner1989, Dynamic Capital Structure Choice: Theory and Tests, Journal of Finance 44, 19-40.

Flannery, Mark, 1986, Asymmetric Information and Risky Debt Maturity Choice, Journal of Finance 41, 19-37.

Gertner and Scharfstein, 1991, A Theory of Workouts and the Effects of Reorganization Law, Journal of Finance 46, 1189-1222.

Guedes, J., and T. Opler, 1996, The Determinants of the Maturity of Corporate Debt Issues, Journal of Finance 51, 1809-1834.

Hackbarth, D., and D. Mauer, 2011, Optimal Priority Structure, Capital Structure, and Investment, Review of Financial Studies, forthcoming.

He, Z., 2011, A Model of Dynamic Compensation and Capital Structure, Journal of Financial Economics 100, 351-366.

He, Z., and W. Xiong, 2011, Dynamic Debt Runs, Review of Financial Studies, forthcoming.

He, Z., and W. Xiong, 2012, Rollover Risk and Credit Risk, Journal of Finance 67, 391-429.

Jensen, M., and W. Meckling, 1976, Theory of the firm: Managerial behavior, agency costs and ownership structure, Journal of Financial Economics 3, 305-360. 
Johnson, S., 2003, Debt Maturity and the Effects of Growth Opportunities and Liquidity Risk on Leverage, Review of Financial Studies 16, 209-236.

Lambrecht, Bart M. and Stewart C. Myers, 2008, Debt and managerial rents in a real-options model of the firm, Journal of Financial Economics 89, 209-231.

Leland, H., 1994a, Corporate Debt Value, Bond Covenants, and Optimal Capital Structure, Journal of Finance 49, 1213-1252.

Leland, H., 1994b, Bond prices, yield spreads, and optimal capital structure with default risk, Working paper, UC Berkeley.

Leland, Hayne, and Klaus Bjerre Toft, 1996, Optimal capital structure, endogenous bankruptcy, and the term structure of credit spreads, Journal of Finance 51, 987-1019.

Leland, H., 1998, Agency Costs, Risk Management, and Capital Structure, Journal of Finance 53, 12131243.

Merton Robert C., 1974, On the Pricing of Corporate Debt: The Risk Structure of Interest Rates. Journal of Finance 29, 449-470.

Moyan, N., 2007, How Big is the Debt Overhang Problem?, Journal of Economic Dynamics \& Control 31, 433-472.

Myers, S., 1977, The Determinants of Corporate Borrowing, Journal of Financial Economics 5, 147-175.

Stohs, M. and D. Mauer, 1996, The Determinants of Corporate Debt Maturity Structure, Journal of Business 69, 279-312.

Titman, S. and S. Tsyplakov, 2007, A Dynamic Model of Optimal Capital Structure, Review of Finance 11(3): 401-451. 


\section{Appendix}

\section{Proof for Proposition 1}

For simplicity denote $V_{0}$ by $V$, and without loss of generality we set $\sigma=1$ (which amounts to an absolute time change). Given $m$ and $F$, it is easy to calculate the second derivative with respect to $V$ as (we use $n(\bullet)$ to denote the density function for normal distribution)

$$
D_{F}(V, F, m)=\frac{n(d)}{F \sqrt{m}}>0, D_{m}(V, F, m)=-\frac{V n(d)}{\sqrt{m}}<0,
$$

And

$$
D_{V V}(V, F, m)=-\frac{n(d)}{V \sqrt{m}}=-\frac{\frac{1}{\sqrt{2 \pi}} \exp \left(-\frac{(\ln (V / F)+0.5 m)^{2}}{2 m}\right)}{V \sqrt{m}}<0 .
$$

For short-term debt with maturity $m_{1}$ and long-term debt with maturity $m_{2}$ where $m_{2}>m_{1}$, Eq. (19) implies that, to maintain the date- 0 debt value, we must have $F_{2}>F_{1}$. Define the difference between these two debt values as $\Delta D(V) \equiv D\left(V, F_{1}, m_{1}\right)-D\left(V, F_{2}, m_{2}\right)$ which, due to Eq. (20), satisfies

$$
\Delta D_{V V}(V)=-\frac{\frac{1}{\sqrt{2 \pi}} \exp \left(-\frac{\left(\ln \left(V / F_{1}\right)+0.5 m_{1}\right)^{2}}{2 m_{1}}\right)}{V \sqrt{m_{1}}}+\frac{\frac{1}{\sqrt{2 \pi}} \exp \left(-\frac{\left(\ln \left(V / F_{2}\right)+0.5 m_{2}\right)^{2}}{2 m_{2}}\right)}{V \sqrt{m_{2}}} .
$$

It is easy to verify that

$$
\Delta D(\infty)=F_{1}-F_{2}<0, \lim _{x \rightarrow 0} \Delta D(x)=0, \lim _{x \rightarrow 0} \Delta D^{\prime}(x)=0 .
$$

Given these results we now show that if $\Delta D(V)=0$ admits positive solutions, then $\Delta D(V)$ only crosses zero at most once from above; note that this result implies that $\Delta D_{V}(V)<0$ whenever $\Delta D^{\prime}(V)=0$, which is the desired result. Suppose that $\Delta D(V)$ crosses 0 from above at some $\hat{V}>0$. Since $\Delta D_{V}(\hat{V})<0$ while $\Delta D_{V}(\infty)=0$, there must exist a region for $V>\hat{V}$ so that $\Delta D(V)$ is convex, which implies that $\Delta D_{V V}$ is positive there. The following lemma is useful.

Lemma 1. Aside from $V=0, \Delta D_{V}$, as a function of $V$, can be zero at most twice.

Proof. For $\Delta D_{V V}=0$ we need

$$
\frac{\exp \left(-\frac{\left(\ln \left(V / F_{1}\right)+0.5 m_{1}\right)^{2}}{2 m_{1}}\right)}{\sqrt{m_{1}}}=\frac{\exp \left(-\frac{\left(\ln \left(V / F_{2}\right)+0.5 m_{2}\right)^{2}}{2 m_{2}}\right)}{\sqrt{m_{2}}}
$$

Rearrange, we reach a quadratic equation for $\ln V$. The result follows easily. QED.

Given this lemma, we now have three cases to consider.

1. Suppose that $\Delta D_{V V}=0$ has no root, which implies that $\Delta D_{V V}>0$. But this cannot be true because it is inconsistent with $\Delta D_{V}(0)=0$ but $\Delta D_{V}(\hat{V})<0$. 
2. Suppose that there exists only one root for $\Delta D_{V V}=0$, which implies that $\Delta D_{V V}(V)$ is initially negative and then turns positive. Therefore, $\Delta D(V)$ is always concave before it turns convex. This implies that there will not exist another solution $V^{\prime}<\hat{V}$ so that $\Delta D\left(V^{\prime}\right)=0$. To see this, note that $\Delta D(0)=0$; then before the earlier solution $V^{\prime}$ at which $\Delta D(V)$ crosses 0 from below, we must have $\Delta D<0$ (the bottom point somewhere between 0 and $V^{\prime}$ ) so that $\Delta D$ is convex. This convex part takes place before the concave part between $V^{\prime}$ and $\hat{V}$, contradiction.

3. Suppose we have two roots for $\Delta D_{V V}=0$. Then it must be first positive, then negative, then positive; i.e., $\Delta D(V)$ is convex first, concave then, and finally turns convex. In words, $\Delta D(V)$ can only be concave in one interval. Now since it is easy to show that $\Delta D_{V}(0)=0$, the initial convexity implies that $\Delta D(V)$ is positive for $V=0+$. Then, for $\Delta D(V)$ to have two solutions after zero, we must have $\Delta D(V)$ to become concave, convex, and then concave again. This contradicts with restriction that $\Delta D(V)$ is concave only in one interval.

\section{Proof for Proposition 2}

The first result follows from Proposition 1. For the second case, without loss of generality set $Q=0$. Consider $V_{2}=V_{0} \exp \left(\tilde{z}_{1}-0.5+\tilde{Z}_{2}-0.5 \widetilde{\sigma_{2}^{2}}\right)$ so that

$$
\tilde{\sigma}_{2}=\left\{\begin{array}{cc}
0 & \text { when } \tilde{Z}_{1}>0 \\
\sigma=\varepsilon & \text { when } \tilde{Z}_{1} \leq 0
\end{array}\right.
$$

where $\varepsilon$ is sufficiently small. When $\sigma=0$, the second period adds no risk, and long-term debt is identical to short-term debt with the same value and overhang. We set $F_{2}=\exp (-0.5)$, so that potential second period noise occurs exactly when the long-term debt is at the money.

We consider a perturbation from $\sigma=0$ to $\sigma=\varepsilon>0$, and comparing the change of overhang effects on each debt. By adjusting $F_{1}$ to ensure that both debts have the same value, we aim to show the following term (where we denote debt overhang by $O H_{t}=D_{t}^{\prime}$ ) is positive

$$
\frac{d O H_{1}}{d \sigma}-\frac{d O H_{2}}{d \sigma}=\frac{d O H_{1}}{d F_{1}} \frac{d F_{1}}{d \sigma}-\frac{d O H_{2}}{d \sigma}=\frac{d O H_{1}}{d F_{1}} \frac{d D_{2} / d \sigma}{d D_{1} / d F_{1}}-\frac{d O H_{2}}{d \sigma} .
$$

We will show that raising $\sigma$ from 0 has no first order effect on long-term debt value $D_{2}$, i.e., $\left.\frac{d D_{2}}{d \sigma}\right|_{\sigma=0}=0$ while $\left.\frac{d O H_{2}}{d \sigma}\right|_{\sigma=0}<0$. Therefore, since $d D_{1} / d F_{1}>0$, we obtain our result. To show these results, we have (note that $Q=\ln F_{2}+0.5$ ) 


$$
\begin{aligned}
D_{2}(\sigma) & =F_{2} \int_{0}^{\infty} n(x) d x+\int_{-\infty}^{0}\left\{\int_{-\infty}^{-x+\frac{\sigma^{2}}{2}} \exp \left(x-\frac{1+\sigma^{2}}{2}+y\right) n\left(\frac{y}{\sigma}\right) \frac{1}{\sigma} d y+F_{2} \int_{0-x+\frac{\sigma^{2}}{2}}^{\infty} n\left(\frac{y}{\sigma}\right) \frac{1}{\sigma} d y\right\} n(x) d x \\
& =F_{2} \int_{0}^{\infty} n(x) d x+F_{2} \int_{-\infty}^{0}\left\{\exp (x) \int_{-\infty}^{-x+\frac{\sigma^{2}}{2}} \frac{1}{\sqrt{2 \pi} \sigma} \exp \left(-\frac{\left(y-\sigma^{2}\right)^{2}}{2 \sigma^{2}}\right) d y+\int_{-x+\frac{\sigma^{2}}{2}}^{\infty} n\left(\frac{y}{\sigma}\right) \frac{1}{\sigma} d y\right\} n(x) d x \\
& \text { let } t=\frac{y-\sigma^{2}}{\sigma} \\
= & F_{2} \int_{0}^{\infty} n(x) d x+F_{2} \int_{-\infty}^{0}\left\{\exp (s) \int_{-\infty}^{-\frac{x}{\sigma}-\frac{\sigma}{2}} n(t) d t+\int_{-\frac{x}{\sigma}+\frac{\sigma}{2}}^{\infty} n(t) d t\right\} n(x) d x
\end{aligned}
$$

Therefore

$$
\begin{aligned}
\frac{d D_{2}(\sigma)}{d \sigma} & =F_{2} \int_{-\infty}^{0}\left\{\exp (x) n\left(-\frac{x}{\sigma}-\frac{\sigma}{2}\right)\left(\frac{x}{\sigma^{2}}-\frac{1}{2}\right)-n\left(-\frac{x}{\sigma}+\frac{\sigma}{2}\right)\left(\frac{x}{\sigma^{2}}+\frac{1}{2}\right)\right\} n(x) d x \\
& =F_{2} \int_{-\infty}^{0}\left\{n\left(-\frac{x}{\sigma}+\frac{\sigma}{2}\right)\left(\frac{x}{\sigma^{2}}-\frac{1}{2}\right)-n\left(-\frac{x}{\sigma}+\frac{\sigma}{2}\right)\left(\frac{x}{\sigma^{2}}+\frac{1}{2}\right)\right\} n(x) d x \\
& =-F_{2} \int_{-\infty}^{0} n\left(-\frac{x}{\sigma}+\frac{\sigma}{2}\right) n(x) d x=-\sigma F_{2} \int_{-\infty}^{0} n\left(-u+\frac{\sigma}{2}\right) n(\sigma u) d u
\end{aligned}
$$

which is zero when $\sigma=0$. However, since

$$
\mathrm{OH}_{2}(\sigma)=1-\int_{0}^{\infty} n(x) d x-\int_{-\infty}^{0} \int_{-x+\frac{\sigma^{2}}{2}}^{\infty} n\left(\frac{y}{\sigma}\right) \frac{1}{\sigma} d y n(x) d x=\int_{-\infty}^{0} n(x) d x-\int_{-\infty}^{0} \int_{-\frac{x}{\sigma}+\frac{\sigma}{2}}^{\infty} n(t) d t n(x) d x
$$

And the first order effect on overhang by raising $\sigma$ is

$$
\begin{aligned}
& \frac{d O H_{2}(\sigma)}{d \sigma}=\int_{-\infty}^{0} n\left(-\frac{x}{\sigma}+\frac{\sigma}{2}\right)\left(\frac{x}{\sigma^{2}}+\frac{1}{2}\right) n(x) d x=\int_{-\infty}^{0} n\left(-\frac{x}{\sigma}+\frac{\sigma}{2}\right)\left(\frac{x}{\sigma}+\frac{\sigma}{2}\right) n(x) \frac{1}{\sigma} d x \\
& \stackrel{\text { let } t=\frac{x}{\sigma}+\frac{\sigma}{2}}{=} \int_{-\infty}^{\frac{\sigma}{2}} n(-t+\sigma) \operatorname{tn}\left(\sigma t-\frac{\sigma^{2}}{2}\right) d t \stackrel{\text { let } \sigma=0}{=}-\frac{1}{\sqrt{2 \pi}}<0 .
\end{aligned}
$$

Therefore we proved our second result. QED.

Proof for Proposition 3

Define the following constants:

$$
\begin{aligned}
& \gamma_{1}=\frac{i-0.5 \sigma^{2}+\sqrt{\left(i-0.5 \sigma^{2}\right)^{2}+2 \sigma^{2}(r+f)}}{\sigma^{2}}>0, \gamma_{3}=\frac{i-0.5 \sigma^{2}+\sqrt{\left(i-0.5 \sigma^{2}\right)^{2}+2 r \sigma^{2}}}{\sigma^{2}}>0, \\
& \gamma_{2}=\frac{-0.5 \sigma^{2}+\sqrt{0.25 \sigma^{4}+2 \sigma^{2}(r+f)}}{\sigma^{2}}>0, \delta_{2}=\frac{0.5 \sigma^{2}+\sqrt{0.25 \sigma^{4}+2 \sigma^{2}(r+f)}}{\sigma^{2}}>1 . \\
& \gamma_{4}=\frac{-0.5 \sigma^{2}+\sqrt{0.25 \sigma^{4}+2 r \sigma^{2}}}{\sigma^{2}}>0, \delta_{4}=\frac{0.5 \sigma^{2}+\sqrt{0.25 \sigma^{4}+2 r \sigma^{2}}}{\sigma^{2}}>1 .
\end{aligned}
$$

We need three conditions to determine three constants. They are value matching conditions at $X_{i}$ and $X_{B}$ :

$$
\begin{aligned}
& p+A_{1} X_{i}^{-\gamma_{1}}=p+A_{2} X_{i}^{-\gamma_{2}}+A_{3} X_{i}^{\delta_{2}}, \\
& p+A_{2} X_{B}^{-\gamma_{2}}+A_{3} X_{B}^{\delta_{2}}=\frac{X_{B}}{r} ;
\end{aligned}
$$


and the smooth pasting condition at $X_{i}$ which gives $-\gamma_{1} A_{1} X_{i}^{-\gamma_{1}-1}=-\gamma_{2} A_{2} X_{i}^{-\gamma_{2}-1}+\delta_{2} A_{3} X_{i}^{\delta_{2}-1}$. Solving these three (linear) equations gives the three constants:

$$
A_{3}=\frac{X_{B} / r-p}{\frac{\gamma_{1}+\delta_{2}}{\gamma_{2}-\gamma_{1}} X_{i}^{\gamma_{2}+\delta_{2}} X_{B}^{-\gamma_{2}}+X_{B}^{\delta_{2}}}, A_{2}=A_{3} \frac{\gamma_{1}+\delta_{2}}{\gamma_{2}-\gamma_{1}} X_{i}^{\gamma_{2}+\delta_{2}} \text {, and } A_{1}=A_{2} X_{i}^{\gamma_{1}-\gamma_{2}}+A_{3} X_{i}^{\gamma_{1}+\delta_{2}}
$$

Now we move on to equity. First we show the optimality of threshold investment strategy. Recall the condition that $1>\lambda r$ so that investment is optimal in the first-best scenario. Because at $X_{B}$ the smooth pasting condition implies that $E^{\prime}\left(X_{B}\right)=0$, while $E^{\prime}(X) \rightarrow \frac{1-\lambda i}{r-i}>\lambda$ as $X \rightarrow \infty$ (the first best level with constant default-free debt value), there must exist a solution to $E^{\prime}\left(X_{i}\right)=\lambda$. Suppose that we have multiple solutions. Take the smallest one; to prove the optimality of the threshold strategy, it suffices to show that, given the constructed equity value based on the threshold strategy, we must have $E^{\prime}(X)>\lambda$ for $X>X_{i}$, where $E(X)$ solves the following ODE for $X>X_{i}$ :

$$
r E(X)=X(1-\lambda i)+i X E^{\prime}(X)+\frac{1}{2} \sigma^{2} X^{2} E^{\prime \prime}(X)-\frac{1}{m}(P-D(X)),
$$

and $D(X)=p+A_{1} X^{-\gamma_{1}}$ is given in Proposition 2. Suppose not; then there at least exist two other solutions $X_{1}, X_{2}>X_{i}$ so that $E^{\prime}\left(X_{1}\right)=\lambda$ and $E^{\prime \prime}\left(X_{1}\right)<0 ; E^{\prime}\left(X_{2}\right)=\lambda$ and $E^{\prime \prime}\left(X_{2}\right)>0$. We can find some intermediate point $X_{3} \in\left(X_{1}, X_{2}\right)$ satisfying $E^{\prime}\left(X_{3}\right) \leq \lambda, E^{\prime \prime}\left(X_{3}\right)=0$ and $E^{\prime \prime \prime}\left(X_{3}\right)>0$. Geometrically, $X_{3}$ is the bottom point of $E^{\prime}(X)$ so that the function $E^{\prime}(X)$ is flat and convex at $X_{3}$. But by taking another derivative of the ODE (15) we have

$$
(r-i) E^{\prime}(X)-1+\lambda i=\left(i+\sigma^{2}\right) X E^{\prime \prime}(X)+\frac{1}{2} \sigma^{2} X^{2} E^{\prime \prime \prime}(X)+\frac{1}{m} D^{\prime}(X) .
$$

Evaluating this equation at $X_{3}, D^{\prime}\left(X_{3}\right)>0$ (the constant $A_{1}<0$ in Proposition 3) implies that $(r-i) E^{\prime}\left(X_{3}\right)-1+\lambda i>0$. However, from $E^{\prime}\left(X_{3}\right) \leq \lambda$, we have a contradiction:

$$
(r-i) E^{\prime}\left(X_{3}\right)-1+\lambda i \leq(r-i) \lambda-1+\lambda i=\lambda r-1<0 \text {. }
$$

Now we derive equity value. The firm value $V(X)$ satisfies

$$
V(X)=\left\{\begin{array}{lc}
\frac{X(1-\lambda i)}{r-i}+B_{1} X^{-\gamma_{3}} & X \geq X_{i} \\
\frac{X}{r}+B_{2} X^{-\gamma_{4}}+B_{3} X^{\delta_{4}} & X_{B}<X<X_{i}
\end{array}\right.
$$

We solve for the constants $B_{i}$ 's based on the value matching conditions and smooth pasting conditions:

$B_{3}=\frac{\left(1+\gamma_{3}\right) \frac{i(1-\lambda i)}{r(r-i)} X_{i}^{\gamma_{4}+1}}{\left(\gamma_{3}+\delta_{4}\right) X_{i}^{\delta_{4}+\gamma_{4}}-\left(\gamma_{3}-\gamma_{4}\right) X_{B}^{\gamma_{4}+\delta_{4}}}, B_{2}=-B_{3} X_{B}^{\gamma_{4}+\delta_{4}}$, and $B_{1}=\frac{i(1-\lambda i) X_{i}^{1+\gamma_{3}}}{r(r-i)}+B_{2} X_{i}^{\gamma_{3}-\gamma_{4}}+B_{3} X_{i}^{\gamma_{3}+\delta_{4}}$.

Then we get equity value $E(X)=V(X)-D(X)$.

\section{Appendix for Section 4.1.4}

Based on both $E^{\prime}\left(X_{i}\right)=\lambda$ and $E^{\prime}\left(X_{B}\right)=0$, one can reach the nonlinear equation for $y=X_{i} / X_{B}$ : 


$$
1=\gamma_{3} \frac{i}{r} \frac{1-\delta_{4}-\left(1+\gamma_{4}\right) y^{-\gamma_{4}-\delta_{4}}}{\gamma_{3}+\delta_{4}-\left(\gamma_{3}-\gamma_{4}\right) y^{-\gamma_{4}-\delta_{4}}}+\frac{r-i}{1-\lambda r} \frac{\gamma_{2}+\delta_{2}}{\gamma_{2}-\gamma_{1}}\left(\frac{\frac{\gamma_{1}}{r y}+\frac{\gamma_{1}\left(1+\gamma_{3}\right) \frac{i(1-\lambda r)}{r(r-i)}\left(\gamma_{4}+\delta_{4}\right)}{\left(\gamma_{3}+\delta_{4}\right) y^{\delta_{4}}-\left(\gamma_{3}-\gamma_{4}\right) y^{-\gamma_{4}}}}{\gamma_{2} \frac{\gamma_{1}+\delta_{2}}{\gamma_{2}-\gamma_{1}} y^{\gamma_{2}}-\delta_{2} y^{-\delta_{2}}}\right)
$$

Now given the solution $y$, the default boundary is given by

$$
X_{B}=r p \frac{\gamma_{2} \frac{\gamma_{1}+\delta_{2}}{\gamma_{2}-\gamma_{1}}-\delta_{2} y^{-\delta_{2}-\gamma_{2}}}{\frac{\gamma_{1}+\delta_{2}}{\gamma_{2}-\gamma_{1}}+y^{-\delta_{2}-\gamma_{2}}+\left(\frac{\gamma_{1}+\delta_{2}}{\gamma_{2}-\gamma_{1}}+y^{-\delta_{2}-\gamma_{2}}\right) \frac{y\left(1+\gamma_{3}\right) \frac{i(1-\lambda r)}{r-i}\left(\gamma_{4}+\delta_{4}\right)}{\left(\gamma_{3}+\delta_{4}\right) y^{\delta_{4}}-\left(\gamma_{3}-\gamma_{4}\right) y^{-\gamma_{4}}}+\gamma_{2} \frac{\gamma_{1}+\delta_{2}}{\gamma_{2}-\gamma_{1}}-\delta_{2} y^{-\delta_{2}-\gamma_{2}}}
$$

which further gives $X_{i}=y X_{B}$.

\section{Appendix for Section 4.3.1}

With the investment cost specification in Eq. (7), the equity holders' optimal strategy still features two thresholds $\left(X_{B}, X_{i}\right)$ : The firm invests whenever $X_{t} \geq X_{i}$, does not invest but keeps servicing the debt when $X_{t} \in\left(X_{B}, X_{i}\right)$, and defaults whenever $X_{t}$ drops to $X_{B}$. Given $\left(X_{B}, X_{i}\right)$, the debt valuation remains the same as Proposition 3 , and the equity valuation is given by

$$
E(X)=\left\{\begin{array}{cc}
\frac{X(1-\Delta \lambda i)}{r-i}-\frac{\rho}{r}+C_{1} X^{-\gamma_{3}}-p-A_{1} X^{-\gamma_{1}} & X \geq X_{i} \\
\frac{X}{r}+C_{2} X^{-\gamma_{4}}+C_{3} X^{\delta_{4}}-p-A_{2} X^{-\gamma_{2}}-A_{3} X^{\delta_{2}} & X_{B}<X<X_{i}
\end{array}\right.
$$

with

$$
C_{3}=\frac{\left(1+\gamma_{3}\right) \frac{i(1-\Delta \lambda i)}{r(r-i)} X_{i}^{\gamma_{4}+1}-\frac{\Delta \gamma_{3}}{r}}{\left(\gamma_{3}+\delta_{4}\right) X_{i}^{\delta_{4}+\gamma_{4}}-\left(\gamma_{3}-\gamma_{4}\right) X_{B}^{\gamma_{4}+\delta_{4}}}, C_{2}=-C_{3} X_{B}^{\gamma_{4}+\delta_{4}} \text {, and } C_{1}=X_{i}^{\gamma_{3}}\left[\frac{i(1-\lambda i) X_{i}^{\gamma_{3}}}{r(r-i)}+\frac{\rho}{r}+C_{2} X_{i}^{-\gamma_{4}}+C_{3} X_{i}^{\delta_{4}}\right] \text {. }
$$

We have the smooth pasting condition $E^{\prime}\left(X_{B}\right)=0$. From $\max _{\tilde{i} \in\{0, i\}}\left\{E^{\prime}(X) \tilde{i} X-\rho-\Delta \lambda \tilde{i} X, 0\right\}$ we know that $E^{\prime}\left(X_{i}\right)=\frac{\rho}{i X_{i}}+\Delta \lambda$. Recall $y=X_{i} / X_{B}$, and $\left(y, X_{B}\right)$ satisfies the following system of equations 


$$
\begin{aligned}
& X_{B}=r p \frac{\gamma_{2} \frac{\gamma_{1}+\delta_{2}}{\gamma_{2}-\gamma_{1}}-\delta_{2} y^{-\delta_{2}-\gamma_{2}}}{\frac{\gamma_{1}+\delta_{2}}{\gamma_{2}-\gamma_{1}}+y^{-\delta_{2}-\gamma_{2}}+\left(\frac{\gamma_{1}+\delta_{2}}{\gamma_{2}-\gamma_{1}}+y^{-\delta_{2}-\gamma_{2}}\right)\left[\frac{\left.y\left(1+\gamma_{3}\right) \frac{i(1-\lambda r)}{r-i}-\frac{\Delta_{0} \gamma_{3}}{X_{B}}\right]\left(\gamma_{4}+\delta_{4}\right)}{\left(\gamma_{3}+\delta_{4}\right) y^{\delta_{4}}-\left(\gamma_{3}-\gamma_{4}\right) y^{-\gamma_{4}}}+\gamma_{2} \frac{\gamma_{1}+\delta_{2}}{\gamma_{2}-\gamma_{1}}-\delta_{2} y^{-\delta_{2}-\gamma_{2}}\right.}, \\
& 1=\gamma_{3} \frac{i}{r} \frac{1-\delta_{4}-\left(1+\gamma_{4}\right) y^{-\gamma_{4}-\delta_{4}}}{\gamma_{3}+\delta_{4}-\left(\gamma_{3}-\gamma_{4}\right) y^{-\gamma_{4}-\delta_{4}}}+\frac{r-i}{1-\rho \lambda r} \frac{\gamma_{1}+\delta_{2}}{\gamma_{2}-\gamma_{1}}\left(\frac{\frac{\gamma_{1}}{r y}+\frac{\gamma_{1}\left(1+\gamma_{3}\right) \frac{i(1-\rho \lambda r)}{r(r-i)}\left(\gamma_{4}+\delta_{4}\right)-\frac{\Delta_{0} \gamma_{3}}{X_{B}}\left(\gamma_{4}+\delta_{4}\right)}{\left(\gamma_{3}+\delta_{4}\right) y^{\delta_{4}}-\left(\gamma_{3}-\gamma_{4}\right) y^{-\gamma_{4}}}}{\gamma_{2} \frac{\gamma_{1}+\delta_{2}}{\gamma_{2}-\gamma_{1}} y^{\gamma_{2}}-\delta_{2} y^{-\delta_{2}}}\right) \\
& +\frac{r-i}{1-\rho \lambda r}\left[\frac{\gamma_{3}}{r}\left(\frac{\delta_{4}+\gamma_{4} y^{-\gamma_{4}-\delta_{4}}}{\gamma_{3}+\delta_{4}-\left(\gamma_{3}-\gamma_{4}\right) y^{-\gamma_{4}-\delta_{4}}}\right)+\frac{1}{i}\right] \frac{\Delta_{0}}{y X_{B}} .
\end{aligned}
$$

\section{Proof of Proposition 4}

It is easier to work through $f=1 / m \rightarrow \infty$. In Eq.(13), we see that $\gamma_{1}, \gamma_{2}$ and $\delta_{2}$ are going to infinity at the same order, while other constants are independent of $f$.

From Eq.(16) one can easily show that $y \rightarrow 1$ for $f \rightarrow \infty$, and $y$ as a function of $f$ is given by

$$
y^{\gamma_{2}(f)}=\frac{r-i}{r(1-r \lambda)} \frac{1+\left(1+\gamma_{3}\right) \frac{i(1-r \lambda)}{r-i}}{1+\gamma_{3} i / r},
$$

which is bounded. Hence $y^{\gamma_{2}+\delta_{2}}$ is bounded as well. Based on Eq (17), we have

$$
X_{B}=r p \frac{\gamma_{2}}{1+\left(1+\gamma_{3}\right) \frac{i(1-r \lambda)}{r-i}+\gamma_{2}} .
$$

This immediately implies that $X_{B} \rightarrow r p$, which is the first claim in Proposition 4.

To show the second claim, we need to calculate the endogenous $p$ which achieves the initial debt value target $D_{0}$. Denote the initial assets-in-place by $X_{0}$. Using the solution for $A_{3}$ in Eq (14), one can show that $A_{3} \rightarrow X_{B}^{\gamma_{1}}\left(\frac{X_{B}}{r}-p\right)$, which implies that

$$
p_{0}=\frac{D_{0}-\left(X_{0} / X_{B}\right)^{-\gamma_{1}} X_{B}}{1-\left(X_{0} / X_{B}\right)^{-\gamma_{1}}}
$$

Define $a \equiv 1+\left(1+\gamma_{3}\right) \frac{i(1-r \lambda)}{r-i}>0$ and $b \equiv \frac{r-i}{r(1-r \lambda)} \frac{a}{1+\gamma_{3} i / r}>0$. Then when $f \rightarrow \infty$, Eq. (19)

and (18) can be rewritten as $X_{B}=r p \frac{\gamma_{2}}{a+\gamma_{2}}$ and $y^{\gamma_{2}(f)}=b$. Combining $X_{B}$ equation with Eq. (20) yields $\left(r D_{0}-X_{B}\right) \gamma_{2}=a X_{B}\left(1-\left(X_{0} / X_{B}\right)^{-\gamma_{1}}\right)$ which implicitly defines $X_{B}(f)$. Hence, 


$$
\frac{\partial X_{B}}{\partial f}=-\frac{a X_{B} \gamma^{\prime}(f)\left[\frac{1}{\gamma}-\frac{1}{\gamma}\left(X_{0} / X_{B}\right)^{-\gamma}-\left(X_{0} / X_{B}\right)^{-\gamma} \ln \frac{X_{0}}{X_{B}}\right]}{-a+\gamma+a(1+\gamma)\left(X_{0} / X_{B}\right)^{-\gamma}}
$$

where we have denoted $\gamma_{1}, \gamma_{2}$ by $\gamma$ when $f \rightarrow \infty$. In the denominator, the second term vanishes. In the numerator, the second and third terms vanish relative to the first term. Hence $X_{B}{ }^{\prime}(f) \rightarrow \frac{a X_{B} \gamma^{\prime}(f)}{\gamma^{2}}$. Besides, $y^{\prime}(f) \rightarrow-\frac{y \ln b}{\gamma^{2}} \gamma^{\prime}(f)$. Because $X_{i}=X_{B} y$, we have $X_{i}^{\prime}(f)=(a-\ln b) X_{i} \frac{\gamma^{\prime}(f)}{\gamma^{2}}$, which implies that $X_{i}$ increases in $f$ if $a>\ln b$ holds when $f \rightarrow \infty$. Finally, notice that when $\lambda \rightarrow 0$ so that the investment threshold $X_{i}$ converges to $X_{B}$, one can show that $b=1$ and hence the condition holds always.

\section{Appendix in Section 4.5}

We give the equity and debt value with second stage expansion only. Footnote 18 and $\theta>1$ imply that $\theta X_{B}>p r$. Thus, given the expansion opportunity, the firm value after expansion is $\theta X_{t} / r \geq \theta X_{B} / r$, and debt (equity) holders receive $p\left(\theta X_{t} / r-p \geq 0\right)$.

Define the following constants:

$$
\gamma_{5}(m)=\frac{-0.5 \sigma^{2}+\sqrt{0.25 \sigma^{4}+2 \sigma^{2}(r+1 / m+\xi)}}{\sigma^{2}}>0, \gamma_{6}=\frac{-0.5 \sigma^{2}+\sqrt{0.25 \sigma^{4}+2 \sigma^{2}(r+\xi)}}{\sigma^{2}}>0
$$

with $\gamma_{5}>\gamma_{6}$. Given $X_{B}$ the debt value is $D(X)=p+X_{B}^{\gamma_{5}}\left(\frac{X_{B}}{r}-p\right) X^{-\gamma_{5}}$, the firm value is

$$
V(X)=\frac{X}{r} \frac{r+\xi \theta}{r+\xi}-\frac{X_{B}^{1+\gamma_{6}}}{r} \frac{(\theta-1) \xi}{r+\xi} X^{-\gamma_{6}}=\frac{X}{r}+\frac{X}{r} \frac{(\theta-1) \xi}{r+\xi}\left[1-\left(\frac{X}{X_{B}}\right)^{1+\gamma_{6}}\right] .
$$

and the equity value is

$$
E(X)=V(X)-D(X)=\frac{X}{r} \frac{r+\xi \theta}{r+\xi}-\frac{X_{B}^{1+\gamma_{6}}}{r} \frac{(\theta-1) \xi}{r+\xi} X^{-\gamma_{6}}-p-X_{B}^{\gamma_{5}}\left(\frac{X_{B}}{r}-p\right) X^{-\gamma_{5}} .
$$

The smooth pasting condition $E^{\prime}\left(X_{B}\right)=0$ implies that

$$
X_{B}=\frac{r p \gamma_{5}}{\gamma_{5}-\gamma_{6}+\left(1+\gamma_{6}\right) \frac{r+\xi \theta}{r+\xi}}
$$

It is clear that $X_{B}$ is increasing in $p$. For refinancing frequency $f$ (thus maturity $m$ ), notice that Eq.(21) suggests that $\gamma_{5}^{\prime}(m)<0$ while $\gamma_{6}$ is independent of $m$. Then we have

$$
X_{B}^{\prime}(m)=\frac{\frac{r p \gamma_{5}^{\prime}(m)}{r+\xi}\left(\gamma_{6} \xi(\theta-1)+r+\xi \theta\right)}{\left(\gamma_{5}-\gamma_{6}+\left(1+\gamma_{6}\right) \frac{r+\xi \theta}{r+\xi}\right)^{2}}<0 .
$$




\section{Proof of Proposition 5}

We work through $f$ instead of $m=1 / f$. Recall the debt value is

$$
D=p+X_{B}^{\gamma_{5}}\left(\frac{X_{B}}{r}-p\right) X^{-\gamma_{5}}=p+p\left(\frac{r p \gamma_{5}}{\gamma_{5}-\gamma_{6}+\left(1+\gamma_{6}\right) \frac{r+\xi \theta}{r+\xi}}\right)^{\gamma_{5}}\left(\frac{\gamma_{6}-\left(1+\gamma_{6}\right) \frac{r+\xi \theta}{r+\xi}}{\gamma_{5}-\gamma_{6}+\left(1+\gamma_{6}\right) \frac{r+\xi \theta}{r+\xi}}\right) X^{-\gamma_{5}} .
$$

We have

$$
\frac{\partial D}{\partial f}=p\left(\frac{-\gamma_{6}+\left(1+\gamma_{6}\right) \frac{r+\xi \theta}{r+\xi}}{\gamma_{5}-\gamma_{6}+\left(1+\gamma_{6}\right) \frac{r+\xi \theta}{r+\xi}}\right)\left(\frac{X_{0}}{X_{B}}\right)^{\gamma_{5}}\left[\ln \left(\frac{X_{0}}{X_{B}}\right)-\frac{\left(1+\gamma_{6}\right) \frac{(\theta-1) \xi}{r+\xi}}{\gamma_{5}-\gamma_{6}+\left(1+\gamma_{6}\right) \frac{r+\xi \theta}{r+\xi}}\right]
$$

And

$$
\frac{\partial D}{\partial p}=1-\left(\frac{X_{B}}{X_{0}}\right)^{\gamma_{5}}-\frac{\gamma_{5}\left(1+\gamma_{6}\right) \frac{(\theta-1) \xi}{r+\xi}}{\gamma_{5}-\gamma_{6}+\left(1+\gamma_{6}\right) \frac{r+\xi \theta}{r+\xi}}\left(\frac{X_{B}}{X_{0}}\right)^{\gamma_{5}}
$$

When $X_{0}$ is sufficiently close to $X_{B}$, i.e., the initial debt value is too high, it is possible that $\frac{\partial D_{0}}{\partial p}<0$, i.e., the debt value is decreasing in $p$. Then equity holders should reduce $p$, which reduces $X_{B}$ in Eq. (22), and equity holders can find another $\hat{p}$ so that $\frac{\partial D}{\partial p}>0$ but still keeping the date zero debt value $D_{0}$. As $X_{B}$ is lower for $\hat{p}$, the firm value and thus the equity value increases. Hence, we know that without loss of generality we can focus on $\frac{\partial D}{\partial p} \geq 0$, i.e., (24) is always positive.

Now we show that $X_{B}$ in (22) is increasing in $f$. We need to check the following is positive

$$
\left.\frac{d X_{B}}{d f}\right|_{\text {Keep D }}=\left[r p \gamma_{5}^{\prime}(f)+r p^{\prime}(f) \gamma_{5}\right]\left(\gamma_{5}-\gamma_{6}+\left(1+\gamma_{6}\right) \frac{r+\xi \theta}{r+\xi}\right)-r p \gamma_{5}^{\prime}(f) \gamma_{5} \text {, }
$$

where $p^{\prime}(f)=-\frac{\partial D / \partial f}{\partial D / \partial p}$ with partial derivatives are given in (23) and (24). Rearranging and collecting terms, we arrive at

$$
\frac{d X_{B}}{d f}=\operatorname{sign}\left[\frac{1-\left(\frac{X_{B}}{X_{0}}\right)^{\gamma_{5}}+\gamma_{5}\left(\frac{X_{B}}{X_{0}}\right)^{\gamma_{5}} \ln \left(\frac{X_{B}}{X_{0}}\right)}{1-\left(\frac{X_{B}}{X_{0}}\right)^{\gamma_{5}}-\frac{\gamma_{5}\left(X_{B} / X_{0}\right)^{\gamma_{5}}\left(1+\gamma_{6}\right) \frac{\xi(\theta-1)}{r+\xi}}{\gamma_{5}-\gamma_{6}+\left(1+\gamma_{6}\right) \frac{r+\xi \theta}{r+\xi}}}\right] .
$$


The denominator, which is Eq. (24), is always positive. We need to show that the numerator is positive as well. To see this, let $z \equiv\left(X_{B} / X_{0}\right)^{\gamma_{5}} \in(0,1)$ as $X_{0}>X_{B}$. Therefore, the above condition is equivalent to $1-z+z \ln z>0$ which easily holds (as its derivative is negative for $z \in(0,1)$ while equals zero when $z=1$ ). Hence, $\frac{d X_{B}}{d f}>0$ and thus $\frac{d X_{B}}{d m}<0$. 